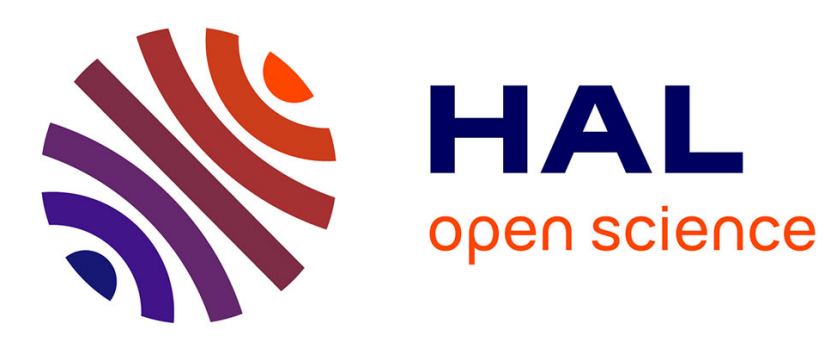

\title{
Avoiding the Cost of your Conscience: Belief Dependent Preferences and Information Acquisition
}

Claire Rimbaud, Alice Soldà

\section{To cite this version:}

Claire Rimbaud, Alice Soldà. Avoiding the Cost of your Conscience: Belief Dependent Preferences and Information Acquisition. 2021. halshs-03325963

\section{HAL Id: halshs-03325963 \\ https://shs.hal.science/halshs-03325963}

Preprint submitted on 25 Aug 2021

HAL is a multi-disciplinary open access archive for the deposit and dissemination of scientific research documents, whether they are published or not. The documents may come from teaching and research institutions in France or abroad, or from public or private research centers.
L'archive ouverte pluridisciplinaire HAL, est destinée au dépôt et à la diffusion de documents scientifiques de niveau recherche, publiés ou non, émanant des établissements d'enseignement et de recherche français ou étrangers, des laboratoires publics ou privés. 


\title{
GATE

UMR 5824

93. chemin des Mouilles 69130 Ecully - France

Maison de l'Université, Bâtiment B 10, rue Trefilerie 42023 Saint-Etienne cedex $02 \cdot$ France http://www.gate.cnrs.fr gate@gate.cnrs.fr

WP 2114 - August 2021

\section{Avoiding the Cost of your Conscience: Belief Dependent Preferences and Information Acquisition}

\author{
Claire Rimbaud, Alice Soldà
}

\begin{abstract}
:
Pro-social individuals face a trade-off between their monetary and moral motives. Hence, they may be tempted to exploit the uncertainty in their decision environment in order to reconcile this trade-off. In this paper, we investigate whether individuals with belief-dependent preferences avoid the monetary cost of behaving according to their moral standards by strategically acquiring information about others'expectations. We test the predictions of an information acquisition model in an online experiment. We use a modified trust-game in which we introduce uncertainty about the second movers' beliefs about first-movers' expectations. Our design enables to (i) identify participants with belief-based preferences and (ii) investigate their information acquisition strategy.Consistent with our predictions of subjective preferences, we find that most individuals classified as belief-dependent strategically select their source of information to avoid the cost of their conscience.
\end{abstract}

\section{Keywords:}

Belief-dependent preferences, illusory preferences, information acquisition, self-serving biases, experiment

JEL codes:

C91 


\title{
Avoiding the Cost of your Conscience: Belief Dependent Preferences and Information Acquisition
}

\author{
Claire Rimbaud ${ }^{a}$ and Alice Soldà ${ }^{b}$
}

July 13, 2021

\begin{abstract}
Pro-social individuals face a trade-off between their monetary and moral motives. Hence, they may be tempted to exploit the uncertainty in their decision environment in order to reconcile this trade-off. In this paper, we investigate whether individuals with belief-dependent preferences avoid the monetary cost of behaving according to their moral standards by strategically acquiring information about others' expectations. We test the predictions of an information acquisition model in an online experiment. We use a modified trust-game in which we introduce uncertainty about the second movers' beliefs about first-movers' expectations. Our design enables to (i) identify participants with belief-based preferences and (ii) investigate their information acquisition strategy.Consistent with our predictions of subjective preferences, we find that most individuals classified as belief-dependent strategically select their source of information to avoid the cost of their conscience.
\end{abstract}

JEL code: C91

Keywords: Belief-dependent preferences, illusory preferences, information acquisition, self-serving biases, experiment

${ }^{a}$ Univ Lyon, Université Lumière Lyon 2, GATE UMR 5824, F-69130 Ecully, France, France. E-mail: rimbaud@gate.cnrs.fr

${ }^{b}$ Heidelberg University, Department of Economics, Bergheimer Str. 20, 69115 Heidelberg, Germany. E-mail: alice.solda@awi.uni-heidelberg.de

Acknowledgements: We are grateful to Giuseppe Attanasi, Si Chen, Christoph Vanberg, and Marie Claire Villeval for useful feedbacks. Helpful comments were received from participants to the GATE-Lab and AWI internal seminar series, and the Lyon-Maastricht workshop. This study has been funded by the LABEX CORTEX (ANR-11-LABX-0042) of Université de Lyon, within the program Investissements d'Avenir (ANR-11-IDEX-007) operated by the French Agence Nationale de la Recherche (ANR). 


\section{Introduction}

A large body of evidence has showed that individuals often care about the welfare of others. ${ }^{1}$ These pro-social individuals face a trade-off between their monetary and moral motives. Hence, they might be tempted to exploit the uncertainty in their decision environment in order to reduce the tension between the two motives. In a seminal paper, later replicated by Larson and Capra (2009) and Feiler (2014), Dana et al. (2007) exposed this trade-off and coined the term "illusory" preferences, which refers to other-regarding preferences that fade away when introducing uncertainty on the relationship between actions and outcomes. ${ }^{2}$ The authors found significantly less generous behavior when participants were unsure about the consequences of their choice on others' payoffs. ${ }^{3}$ This phenomenon has been supported by subsequent research. It has been shown that, in order to behave more selfishly, individuals manipulated their beliefs about others' intentions (Di Tella et al., 2015; Andreoni and Sanchez, 2020), remained strategically ignorant about the consequences of their choices (Grossman and Van Der Weele, 2017; Kajackaite, 2015), and took advantage of the presence of risk or ambiguity on whether donations were actually implemented (Haisley and Weber, 2010; Exley, 2016; Garcia et al., 2020). In the field, studies found that individuals avoided information on the environmental consequences of their actions (d'Adda et al., 2018) and news that could raise their empathy about refugees (Freddi, 2019).

This growing body of evidence has focused on outcome-based preferences, i.e., preferences over payoffs. Yet, pro-social behavior can also be shaped by belief-based preferences, i.e., preferences over payoffs and beliefs. To illustrate how these different types of preferences work, let's take an example. Ann offers Bob to work on a project together. Ann holds private expectations

\footnotetext{
${ }^{1}$ For instance, people donate positive amounts of money to others without any strategic incentives to do so (Forsythe et al., 1994) or prefer more equitable monetary allocations over selfish ones (Fehr and Schmidt, 1999; Bolton and Ockenfels, 2000). People donate more when their recipient expects to receive more (Bellemare et al., 2018; Attanasi et al., 2019), or lie less often when others' can infer their degree of dishonesty (Dufwenberg and Dufwenberg, 2018)

${ }^{2}$ Throughout this paper we refer to this term more loosely as preferences that fade away in the presence of uncertainty in the decision environment. In particular, we use the concept of "subjective" preferences introduced by Spiekermann and Weiss (2016) to describe preferences defined over the epistemic state of the world rather than the actual state of the world.

${ }^{3}$ Serra-Garcia and Szech (2019) showed that this demand for less information is sensitive to the cost of avoiding the information.
} 
about how much Bob should work on the project. If Bob is a purely selfish, he maximizes his utility function by providing zero effort, regardless of his beliefs about Ann's expectations. In contrast, Bob may be sensitive to Ann's expectations. If this is the case, Bob's beliefs about Ann's expectations can affect his level of effort in two directions. If Bob is guilt-averse, he maximizes his utility function by not disappointing others' expectations (Battigalli and Dufwenberg, 2007). Hence, his effort will increase with his beliefs about Ann's expectations. If, instead, Bob is intention-based reciprocal, he maximizes his utility function by repaying (un)kindness with (un)kindness (Dufwenberg and Kirchsteiger, 2004, 2019). If this is the case, an increase in his beliefs about Ann's expectations reduces how kind he perceives Ann to be. Consequently, his effort will decrease with his beliefs about Ann's expectations.

Results on the potentially "illusory" nature of belief-dependent preferences are mixed. Experimental studies addressing this question typically focused on reciprocity in trust games where the first-mover was uncertain about the second-mover's responsibility in the final outcome. In such context, the second-mover could, in principle, take advantage of this uncertainty to choose a less pro-social action than they would have in the absence of uncertainty. Van der Weele et al. (2014) showed that second-movers did not react to the introduction of uncertainty. In contrast, Regner (2018) and Regner and Matthey (2017) reported more selfish choices from second-movers. Furthermore, Friedrichsen et al. (2020) showed that reciprocity was lower when the first-mover's intentions were hidden.

To the best of our knowledge, there is no study on the potential "illusory" nature of guiltaversion. Two related studies lead to contrasted conclusions. Grubiak (2019) revealed that a substantial fraction of participants did not exploit the uncertainty about the relationship between their effort and their partner's outcome to break their promises. We interpret this finding as tentative evidence that guilt-aversion is not sensitive to the presence of situational excuses. In contrast, Inderst et al. (2019) found that second-movers in a trust game were less guilt-averse when the responsibility over the first-mover's payoff was shared between the first- and secondmovers. This challenges the robustness of guilt aversion since participants were prone to exploit 
situational excuses to avoid being pro-social.

In this paper, we investigate whether decision-makers with belief-dependent preferences selfservingly bias their information acquisition strategy in order to minimize the tension between their monetary interest and their belief-dependent concern. To address this question, we adapt the model of endogenous information acquisition by Spiekermann and Weiss (2016) to two specific belief-dependent preferences: guilt-aversion and reciprocity. In our framework, the secondmover ("trustee") in a modified trust game is uncertain about the first-mover's ("trustor") expectations, and can acquire information to resolve this uncertainty. Trustees can choose between two information sources. Each source provides either an informative signal about the trustor's expectations, or a null signal. A specific source can produce one of two types of informative signals, namely Low (i.e., trustor's expectations are low) or High (i.e., trustor's expectations are high), but never both.

Our model relies on two key features. First, we allow preferences to be "subjective" (i.e., to depend on what trustees believe about the trustor's expectations). This is crucial as it creates an opportunity for subjective trustees to bias their acquisition of information in order to manipulate their beliefs about others' expectations. For objective trustees (i.e., whose preferences depend on the trustor's actual expectations), there is no such opportunity given that the actual expectations of other players cannot be changed by any information acquisition strategy. ${ }^{4}$ Second, we impose a coarse-grained mapping of beliefs, that is a mapping where beliefs can correspond to only three states: knowing with certainty that others' expectations are Low, knowing with certainty that they are High, or remaining uncertain. Hence, acquiring information from a Low source never reveals with certainty that the expectations are High, and vice versa. Given this feature, full information avoidance is never an optimal strategy for subjective trustees, regardless of their belief-dependent motive.

\footnotetext{
${ }^{4}$ Other models based on different mechanisms can also predicts strategic information acquisition by assuming belief-dependent preference, such as the model of moral constraints by (Rabin, 1995), selfsignaling theories (e.g., (Grossman and Van Der Weele, 2017)) or a model relying on an aversion to harm others (Chen et al., 2020).
} 
We demonstrate that trustees with objective belief-dependent preferences should acquire signals from both information sources, regardless of their belief-dependent motive, so that they maximise their chances to implement the optimal decision given others' actual expectations. In contrast, trustees with subjective belief-dependent preferences should acquire the signal that reduce the conflict between their monetary payoff and their belief-dependent motive. Hence, a guilt-averse trustee will only seek a Low signal (as guilt-averse trustees can keep more for themselves by holding the belief that the trustor's expectations are low). Symmetrically, a reciprocal trustee will only seek a High signal (as reciprocal trustees can keep more for themselves by holding the belief that the trustor's expectations are high).

We then examine the different information acquisition strategies of trustees in an online experiment. As in the theoretical framework, we keep trustees uncertain about the trustors' outside option. In order to identify belief-dependent trustees, we first manipulate the trustors' outside option, which can be either Low or High. This manipulation aims to generate an exogeneous variation in trustees' beliefs: the higher the trustors' outside option, the higher the trustees' beliefs about the trustors' expectations. We then elicit trustees' return decisions conditional on learning that the trustor's outside option is either Low or High. Trustees are then unexpectedly given the opportunity to acquire information about the trustor's actual outside option, which will determine their final transfer. Trustees can either (i) acquire a High signal and learn with $50 \%$ chance that the trustor outside option is High if it is truly the case, or remain uninformed; (ii) acquire a Low signal and learn with $50 \%$ chance that the trustor outside option is Low if it is truly the case, or remain uninformed; (iii) acquire both a Low and a High signal. If trustees learn the trustor's outside option, the corresponding conditional return is implemented. If trustees remain uninformed about the trustor's outside option, the average of both conditional returns is implemented. Based on their choice of information acquisition, we can assess whether trustees strategically seek signals that are congruent with their monetary incentives rather seeking signals that maximize their information on the actual expectations of the trustor. 
Consistent with the literature on "illusory" preferences, we find that $60.47 \%$ of guilt-averse trustees (i.e., trustees who indicated a lower return choice conditional on learning that the trustor's outside option is Low compared to High) chose to acquire a Low signal only. ${ }^{5}$ This information acquisition strategy is in line with our theoretical predictions of subjective guiltaversion. In addition, we find that trustees who have the most money to lose from learning about the actual expectations of the trustor, are also the ones who are the most likely to engage in self-serving information acquisition strategies.

This paper closely relates to Spiekermann and Weiss (2016), who investigated whether normbased preferences were "illusory" by giving participants an opportunity to strategically seek and/or avoid information. Our paper departs from theirs in two major ways. First, we focus on belief-based preferences instead of normative choices, i.e. on information about social norms. Furthermore, we allow behavior to be influenced by expectations both negatively and positively. Therefore, we can capture a broader range of behavior than Spiekermann and Weiss (2016).

Our findings contribute to the literature on belief-dependent preferences. A long-standing debate in this literature concerns the best way to let participants know about others' expectations. ${ }^{6}$ Unlike most previous studies where the uncertainty about others' expectation is automatically resolved at the time where the action is implemented, we allow participants to resolve (or not) this uncertainty in a self-serving manner. Furthermore, we contribute to a recent strand of papers calling attention to the limited circumstances in which guilt-aversion is observed. For instance, Morell (2019) suggested that guilt aversion was observed only when social distance is small and Balafoutas and Fornwagner (2017) showed that it occurred when expectations were reasonable. Our findings show that uncertainty about others' beliefs dramatically affects prosocial behavior, which suggest that the extent to which belief-dependent preferences can sustain

\footnotetext{
${ }^{5}$ Note that because only one trustee exhibit intention-based reciprocity preferences consistent with the assumptions of our information acquisition model, we restricted our analyses to guilt-averse and belief independent trustees only.

${ }^{6}$ Beliefs about others' expectations can be self-reported (e.g., Charness and Dufwenberg, 2006), directly communicated (e.g., Ellingsen et al., 2010), induced via hypothetical alternatives (e.g., Khalmetski et al., 2015) or induced via social norms (e.g., Balafoutas and Sutter, 2017).
} 
pro-social behavior may be overstated in the existing literature. Finally, our experimental design allows us to compare the relative weight of reciprocal vs. guilt-averse preferences in a randomly selected sample of the MTurk population. Consistent with Attanasi et al. (2010), our results suggest that guilt-aversion is the predominant motive in interactions in which the decision-maker's choice set is determined by a first-mover's willingness to blindly trust him/her.

In addition, our findings contribute to the literature on strategic information acquisition. While there is extensive evidence that individuals can deliberately remain ignorant about the consequences of their actions (see Golman et al., 2017 for a review), ${ }^{7}$ a small body of research has now showed that individuals can also actively seek information if, in expected terms, selfish justifications become more available by doing so. When the information acquisition choice was binary, Fong and Oberholzer-Gee (2011) found that dictators who chose to acquire information about why their recipient was "poor", used it as an excuse to reduce their donations. When information was acquired sequentially, individuals stopped collecting information earlier when they liked early returns. ${ }^{8}$ We differentiate ourselves from these lines of research by focusing on situations in which individuals can discriminate between sources of information. In this literature, individuals have been shown to choose uninformative advisers (Shalvi et al., 2019), select positive feedback about their performance (Solda et al., 2019) or collect information on the (un)deservingness of recipients (Spiekermann and Weiss, 2016). Our findings add to this emergent literature by showing that individuals can also strategically discriminate between information sources when information relates to others' expectations.

The remaining of the paper is organised as follows. We develop our theoretical model in Section 2. In Section 3, we present the experimental design used to address our research question. Next, we derive our experimental hypotheses in Section 4. In Section 5, we describe our empirical results. Finally, we conclude in Section 6.

\footnotetext{
${ }^{7}$ In particular, Xiao and Bicchieri (2012) showed that information avoidance can be relevant in the context of empirical expectations. The authors found that, when there is a small cost to acquire information, dictators avoid information on injuctive or descriptive norms about giving.

${ }^{8}$ For instance, information about their health (Ditto and Lopez, 1992), others' personal traits (Smith et al., 2017) or the harm they may do to others (Chen et al., 2020).
} 


\section{Theoretical Model}

We introduce a Quasi-Trust game with incomplete information. The first mover ("trustor") decides between two actions: In or Out. If the trustor chooses In, the second mover ("trustee") receives an endowment $E$ to allocate between himself and the trustor. ${ }^{9}$ The trustee returns $y$ (with $0 \leq y \leq E$ ) to the trustor and keeps $E-y$ to himself. If the trustor chooses Out, the game ends and each player receives an outside option. The trustee receives $O^{\text {trustee }}$ and the trustor receives $O_{\omega}^{\text {trustor }}$ which depends on the state of the world $\omega \in\{L($ ow $), H(i g h)\}$, with $O_{H}^{\text {trustor }}>O_{L}^{\text {trustor }}$. The trustor knows the state of the world with certainty when making her decision. In contrast, the trustee does not know the state of the world when choosing $y$, but knows that both states are equally likely to occur, that is: $p=p(\omega=L)=p(\omega=H)=0.5$. The structure of the game is summarized in Figure 1.

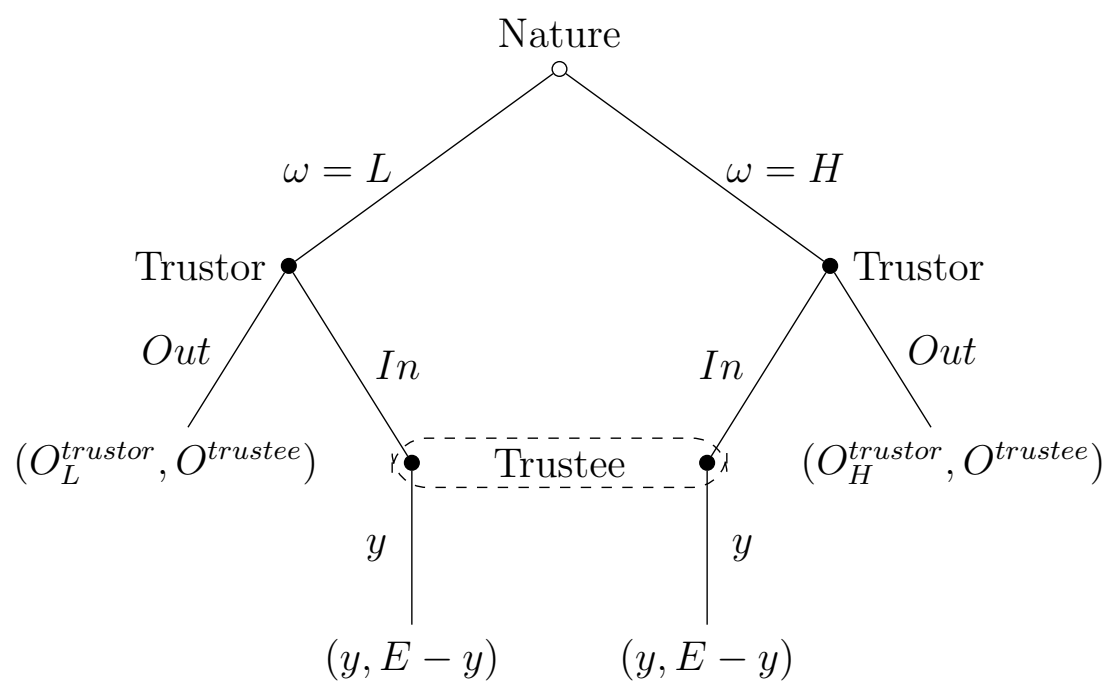

Figure 1: Trust game with High or Low outside option

We define $\phi_{\omega} \in[0, E]$, the trustor's first-order beliefs about his own payoff conditional on choosing In: $\phi_{\omega}=\mathbb{E}^{\text {trustor }}[y \mid \operatorname{In}, \omega]$; and $\Phi_{\omega} \in[0, E]$, the trustee's second-order beliefs about the

\footnotetext{
${ }^{9}$ For the sake of clarity, we use "she/her" when referring to the trustor and "he/him" when referring to the trustee.
} 
trustor's payoff conditional on choosing In: $\Phi_{\omega}=\mathbb{E}^{\text {trustee }}\left[\phi_{\omega}\right]$.

\section{$2.1 \quad$ Belief Formation}

A payoff-maximizing trustor will choose In only if she expects to receive more from doing so than from choosing Out, i.e., when Equation 1 is satisfied.

$$
\phi_{\omega} \geq O_{\omega}^{\text {trustor }}
$$

Consequently, the higher the trustor's outside option is, the higher expectations of returns she signals by choosing In (i.e., the higher her first-order beliefs about her own payoff from choosing In): $\phi_{L} \leq \phi_{H}$. Inferring this, the trustee's second-order beliefs also increase in the trustor's outside option: $\Phi_{L} \leq \Phi_{H}$. This corresponds to an instance of psychological forward induction reasoning (Dufwenberg, 2002). ${ }^{10}$ It leads to the following assumption.

Assumption. Conditional on choosing In, trustors' first-order beliefs and trustees' second-order beliefs are higher when the outside option is High rather than Low.

\section{$2.2 \quad$ Belief-dependent preferences}

We focus on the two main belief-dependent preferences that may be at play in a trust game: guilt-aversion and reciprocity. A guilt-averse trustee dislikes to disappoint others' expectations (Battigalli and Dufwenberg, 2007). His utility function corresponds to his material payoff minus the guilt he experiences (Equation 2). His guilt corresponds to the difference (if positive) between the trustor's expected payoff and the trustor's actual payoff. This difference is weighted by his sensitivity to guilt, denoted $\gamma_{i} \geq 0$ (Equation 3).

$$
\begin{aligned}
u_{g, i}\left(y, \Phi_{\omega}\right) & =(E-y)-g\left(y, \Phi_{\omega}\right) \\
\text { with } g_{i}\left(y, \Phi_{\omega}\right) & =\gamma_{i} \cdot \max \left\{0,\left(\Phi_{\omega}-y\right)\right\}
\end{aligned}
$$

\footnotetext{
${ }^{10}$ Experimental evidence in favor of the psychological forward induction reasoning was provided by Woods and Servátka (2016).
} 
If $\gamma_{i}<1, u_{g, i}\left(y, \Phi_{\omega}\right)$ is maximized for $y^{*}=0$ whereas, if $\gamma_{i}>1, u_{g, i}\left(y, \Phi_{\omega}\right)$ is maximized for $y^{*}=\Phi_{\omega} \cdot{ }^{11}$ Proposition 1 follows below.

Proposition 1. If $\gamma_{i}<1$, guilt-averse trustees return $y^{*}=0$. If $\gamma_{i}>1$, guilt-averse trustees return $y^{*}=\Phi_{\omega}$.

A reciprocal trustee likes to repay (un)kindness with (un)kindness (Dufwenberg and Kirchsteiger, 2004). His utility function corresponds to his material payoff plus the pleasure from reciprocating (Equation 4). The pleasure from reciprocating (Equation 5) is the product of the trustor's perceived kindness toward the trustee (Equation 6) and the trustee's kindness toward the trustor (Equation 7). The product is weighted by his sensitivity to reciprocity denoted $\rho_{i} \geq 0$. To define the trustor's perceived kindness, we compare the payoff that the trustee would receive, given the trustor's expectations $\left(E-\Phi_{\omega}\right)$, to an equitable payoff which corresponds to the average between the worst and the best payoff he can receive, given the trustor's expectations $\left(\pi_{\text {trustee }}^{e}\right)$. To define the trustee's kindness, we compare the payoff the trustor receives from the trustee's action $(y)$ to an equitable payoff $\left(\pi_{\text {trustor }}^{e}\right)$ which corresponds to the average between the worst and the best payoff she can receive from the trustee's action.

$$
\begin{aligned}
u_{r, i}\left(y, \Phi_{\omega}\right) & =(E-y)+r\left(y, \Phi_{\omega}\right) \\
\text { with } r_{i}\left(y, \Phi_{\omega}\right) & =\rho_{i} \cdot \lambda\left(\Phi_{\omega}\right) \cdot k(y) \\
\text { with } \lambda\left(\Phi_{\omega}\right) & =\left(E-\Phi_{\omega}\right)-\pi_{\text {trustee }}^{e}=\left(E-\Phi_{\omega}\right)-\frac{\left(E-\Phi_{\omega}\right)+O^{\text {trustee }}}{2} \\
& =\frac{E-O^{\text {trustee }}-\Phi_{\omega}}{2} \\
\text { with } k(y) & =y-\pi_{\text {trustor }}^{e}=y-\frac{0+E}{2}=y-\frac{E}{2}
\end{aligned}
$$

If $\Phi_{\omega} \geq E-O^{\text {trustee }}, u_{r, i}\left(y, \Phi_{\omega}\right)$ is maximized for $y^{*}=0 ;^{12}$ the trustor is perceived unkind, and the trustee responds with the least kind option possible. If $\Phi_{\omega}<E-O^{\text {trustee }}$, there is a trade-off between the reciprocity motive (responding with kindness) and the self-interest motive. Therefore, $y^{*}$ depends on the relative weight of the material payoff, 1 , and of the

\footnotetext{
${ }^{11}$ If $\gamma_{i}=1$, then $u_{g, i}=E-\Phi_{\omega}$, hence the solution is indeterminate: $y^{*} \in[0, E]$.

${ }^{12}$ When $\Phi_{\omega}=E-O^{\text {trustee }}$, this is a special case where the trustee is purely selfish because Equation 5 is null.
} 
kindness function, $\rho_{i} \cdot \lambda\left(\Phi_{\omega}\right)$. If $\rho_{i}<\frac{2}{E-O^{\text {trustee }}-\Phi_{\omega}}, u_{r, i}\left(y, \Phi_{\omega}\right)$ is maximized for $y^{*}=0$, whereas if $\rho_{i}>\frac{2}{E-O^{\text {trustee }}-\Phi_{\omega}}, u_{r, i}\left(y, \Phi_{\omega}\right)$ is maximized for $y^{*}=E .^{13}$

Proposition 2. If $\Phi_{\omega} \geq E-O^{\text {trustee }}$, that is if the trustor is perceived as unkind, reciprocal trustees return $y^{*}=0$. If $\Phi_{\omega}<E-O^{\text {trustee }}$, that is the trustor is perceived as kind, and if (i) $\rho_{i}<\frac{2}{E-O^{t r u s t e e}-\Phi_{\omega}}$, reciprocal trustees return $y^{*}=0$ or (ii) $\rho_{i}>\frac{2}{E-O^{\text {trustee }}-\Phi_{\omega}}$, reciprocal trustees return $y^{*}=E$.

For the remaining of the analysis, we introduce $f_{i}(y, \Phi)$, the psychological component of the utility function. When a trustee is guilt averse, then $f_{i}(y, \Phi)=g_{i}(y, \Phi)$; when a trustee is reciprocal, then $f_{i}(y, \Phi)=r_{i}(y, \Phi)$; and when the trustee does not have belief-dependent preferences, then $f_{i}(y, \Phi)=0$.

To reflect many real-life situations, we focus on cases where there exists a trade-off between the monetary payoff and the psychological component of the utility function, that is when $y^{*}>0$ in at least one state of the world. Hence, we restrict our analysis to sufficiently guilt-averse $\left(\gamma_{i}>1\right)$ and sufficiently reciprocal $\left(\rho_{i}>\frac{2}{E-O^{\text {trustee }}-\Phi_{\omega}}\right)$ trustees, and constrain our framework such that the trustor is always perceived as kind when choosing $\operatorname{In}\left(\Phi_{\omega}<E-O^{\text {trustee }}\right)$.

\subsection{Information Acquisition Strategy}

First, we define the trustees' decision problem under certainty about the true state of the world. Let $\hat{u}_{g, i}\left(\Phi_{\omega}\right)=\max _{y} u_{g, i}\left(y, \Phi_{\omega}\right)$ be a guilt-averse trustee's maximum utility achievable for a given expectation. This function decreases with $\Phi$ : the higher the expectations of the trustor, the less the trustee keeps for himself. Symmetrically, let $\hat{u}_{r, i}\left(\Phi_{\omega}\right)=\max _{y} u_{r, i}\left(y, \Phi_{\omega}\right)$ be a reciprocal trustee's maximum utility achievable for a given expectation. This function increases with $\Phi$ : the higher the expectations of the trustor, the lower the perceived kindness, the more the trustee keeps for himself. ${ }^{14}$ The proof is provided in Section A.1. Recalling our auxiliary assumption which states that $0 \leq \Phi_{L}<\Phi_{H} \leq E$, it follows that $\hat{u}_{g, i}\left(\Phi_{L}\right)>\hat{u}_{g, i}\left(\Phi_{H}\right)$ for a

\footnotetext{
${ }^{13}$ If $\rho_{i}=\frac{2}{E-O^{\text {trustee }}-\Phi_{\omega}}$, then $u_{r, i}=\frac{E}{2}$, hence the solution is indeterminate: $y^{*} \in[0, E]$.

${ }^{14}$ Note that for a reciprocal trustee, this statement holds for $y<\frac{E}{2}$. A detailed discussion of this condition is provided in Section A.1.
} 
guilt-averse trustee and $\hat{u}_{r, i}\left(\Phi_{L}\right)<\hat{u}_{r, i}\left(\Phi_{H}\right)$ for a reciprocal trustee.

Second, we define the decision problem under uncertainty about the true state of the world in a situation where, before choosing how much to return, the trustee can acquire costless signals about the true state of the world. We define $p^{\prime}$ the updated probability of $p$ after the acquisition of signal(s). The trustee can acquire one or two types of signals, represented by the random variables $S_{L}$ and $S_{H}$. With probability $s$, the signal $S_{\omega}$ reveals that the state is $\omega$ given that the state is indeed $\omega\left(S_{\omega}=\omega\right)$, and with probability $1-s$, the signal does not reveal the state of the world (null signal, $S_{\omega}=0$ ). After a null signal, the trustee updates the probability $p$ using Bayes' rule, which yields $p^{\prime}=\frac{(1-s) p}{(1-s) p+(1-p)}$ after $S_{L}=0$ and $p^{\prime}=\frac{p}{p+(1-s)(1-p)}$ after $S_{H}=0$. Receiving a null signal never removes the uncertainty. In fact, for any updated probability $p^{\prime}$, it exists $\epsilon \geq 0$, the margin of tolerance "near certainty", such that $\epsilon<p^{\prime}<1-\epsilon$. Finally, if the trustee receives both $S_{L}=0$ and $S_{H}=0$, no update is necessary as the two signals cancel out each other: $p^{\prime}=p$.

We distinguish between objective and subjective belief-dependent preferences. For an objective trustee, the psychological component depends on the true state of the world. Therefore, $\Phi_{\omega}$ can take two values either $\Phi_{\omega}=\Phi_{L}$ in the Low state or $\Phi_{\omega}=\Phi_{H}$ in the High state. Under uncertainty, an objective trustee cannot be sure to choose the action that minimizes his guilt, or maximize his pleasure from reciprocity. Therefore, an objective guilt-averse (reciprocal) trustee must minimize (maximize) the expected psychological component given by: $p \cdot f_{i}\left(y, \Phi_{L}\right)+(1-p) \cdot f_{i}\left(y, \Phi_{H}\right)$.

For a subjective trustee, the psychological component depends on the epistemic state of the world. We follow Spiekermann and Weiss (2016) in proposing a coarse mapping of beliefs. ${ }^{15} \mathrm{We}$ define $\Phi_{p}$ the step function (Equation 8) corresponding to the three epistemic states: knowing that the true state is Low, $\Phi_{p^{\prime}}=\Phi_{L}$, knowing that the true state is High, $\Phi_{p^{\prime}}=\Phi_{H}$, or not

\footnotetext{
${ }^{15}$ In the context of compliance to social norms, Spiekermann and Weiss (2016, p. 174) argue that "since degrees of beliefs are not observable in detail, it is unlikely that social norms take them as argument with any great precision. [...] This is mirrored in our everyday language rergarding normative choices, in which we rarely refer to degree of beliefs". We consider that the same reasoning applies for belief-dependent preferences.
} 
knowing the true state, $\Phi_{p^{\prime}}=\Phi_{U}$.

$$
\Phi_{p^{\prime}}=\left\{\begin{array}{l}
\Phi_{L} \text { if } p^{\prime} \geq 1-\epsilon \\
\Phi_{U} \text { if } \epsilon<p^{\prime}<1-\epsilon \\
\Phi_{H} \text { if } p^{\prime} \leq \epsilon
\end{array}\right.
$$

What is the optimal information acquisition for a belief-dependent trustee depending on whether his preferences are objective or subjective? Recall that trustees can choose to acquire (i) $S_{L}$ only, (ii) $S_{H}$ only, or (iii) both $S_{L}$ and $S_{H}$. Given $y^{*}$, an objective belief-dependent trustee maximizes his utility when his return matches the true state of the world, that is, when he learns the true state of the world. Hence, the information acquisition strategy that maximizes his utility is to acquire both signals, as it maximizes his chances to learn about the true state of the world. The proof is provided in Section A.2.

Proposition 3. Objective belief-dependent trustees acquire both signals, regardless of their beliefdependent motives.

In contrast, a subjective belief-dependent trustee maximizes his utility if his return matches what he believes about the true state of the world. A subjective guilt-averse trustee minimizes the conflict between monetary payoff and guilt when he holds the belief that the state of the world is low (recall that under certainty, $\hat{u}_{g, i}\left(\Phi_{L}\right)>\hat{u}_{g, i}\left(\Phi_{H}\right)$ ). Consequently, a subjective guiltaverse trustee will sample information from the signal $S_{L}$ only, which provides either information congruent with that beliefs, or no information. Symmetrically, a subjective reciprocal trustee minimize the conflict between monetary payoff and the pleasure from reciprocity when the state of the world is High (recall that under certainty, $\hat{u}_{r, i}\left(\Phi_{H}\right)>\hat{u}_{r, i}\left(\Phi_{L}\right)$ ). Consequently, a subjective reciprocal trustee will sample information from the signal $S_{H}$ only, which provides either information congruent with that beliefs, or no information. The proof is provided in Section A.3.

Proposition 4. Subjective belief-dependent trustees with a coarse mapping of beliefs will acquire a Low signal only if they are guilt-averse, and acquire a High signal only if they are reciprocal. 


\section{Design}

In order to test our main theoretical predictions, we designed an experiment that mimics the theoretical framework described in Section 2. Within this framework, we first introduced uncertainty about the trustors' expectations, and then provided trustees' with an opportunity to acquire information to alleviate this uncertainty.

Trust game. At the beginning of the experiment, participants were randomly allocated to either the role of trustor or the role of trustee. Trustors faced two options: Out and In. If they chose Out, the game ended and both type of players received an outside option. The trustees' outside option was equal to 90 cents. ${ }^{16}$ In contrast, the trustors' outside option depended on the game being played. If trustors chose In, they forewent their outside option. As a consequence, trustees received 200 cents to allocate between themselves and their matched trustor in increment of 15 cents. Players were informed of the entire payoff structure, including the existence of two equally likely outside options for trustors at the time of decision. Trustors were informed about their own outside option before they made their decision. In contrast, trustees did not know the trustors' actual outside option at the time of decision.

Outside option manipulation. In the Low game, trustors received 15 cents if they chose Out. In contrast, trustors received 75 cents if they chose Out in the High game. This feature of the design creates an exogenous variation in the participant's beliefs about the trustor's expected payoffs from choosing In. We operate under the assumption that trustors who chose In expect a return at least equal to the outside option that they were willing to forego. Therefore, conditional on choosing In, (i) trustors' first-order beliefs about their own payoff should be higher when the outside option is High rather than Low, and (ii) anticipating this, trustees' second-order beliefs about the trustors' payoff should also be higher when the outside option is High rather than Low.

Beliefs elicitation. Before both trustors and trustees made their decisions, we elicited

\footnotetext{
${ }^{16}$ All amounts are in USD.
} 
their conditional beliefs about the trustors' expected payoffs from choosing In. To do so, we asked trustors to indicate how much they expected their trustee to send them if they chose In, both in the Low game and the High game. The elicitation of trustors' first-order beliefs was incentivized. Trustors' beliefs corresponding to the true state of the world were matched with their trustee's decision in the corresponding state of the world. If a trustor's belief was accurate, with a 15 cents margin of error, she was paid 50 cents. Symmetrically, we asked trustees to indicate how much trustors expected to receive if they chose In, both in the Low game and the High game. The elicitation of trustees' second-order beliefs was incentivized using the the same procedure described above. Trustees' beliefs corresponding to the true state of the world were matched with their trustor's belief in the corresponding state of the world. Trustees received 50 cents if their beliefs were accurate with a 15 cents margin of error.

Trustee's return choices. Trustees did not know their trustor's actual outside option at the time of decision. Hence, we elicited how much trustees wanted to send to the trustor both in case they learned that the outside option was Low (Decision Low) and in case they learned that the outside option was High (Decision High). ${ }^{17}$ This key feature of the design, inspired by the "menu" method of Bellemare et al. (2011), is crucial to identify trustees with belief-dependent preferences. Indeed, because trustors' outside options were designed to induce a shift in beliefs, eliciting trustees' returns conditional on their knowledge of the different outside options was equivalent to eliciting their choices conditional on the trustors' first-order beliefs. ${ }^{18}$ Trustees were informed that if they learned before the end of the experiment that the trustor's actual outside option was Low, Decision Low would be implemented. Symmetrically, if they learned that the trustor's actual option was High, Decision High would be implemented. If they remained uninformed about their trustor's actual outside option, the trustor would receive the average of Decision Low and Decision High. ${ }^{19}$

\footnotetext{
${ }^{17}$ Note that because trustees did not observe the trustor's decision, they were asked to make a decision in the eventuality that their trustor chose In (strategy method).

${ }^{18} \mathrm{~A}$ similar procedure was used by Khalmetski (2016).

${ }^{19}$ Note that the model requires that $y_{L}<y_{U}<y_{H}$. Setting $y_{U}=\frac{y_{L}+y_{H}}{2}$ has the advantage to reflect the expected transfer under uncertainty without introducing probabilities to the participants.
} 
Trustee's information acquisition. After making their conditional transfer decisions, trustees were unexpectedly offered the opportunity to acquire information about their trustor's outside option. To do so, we used the same procedure as in Spiekermann and Weiss (2016). Trustees faced two potential sources of information that took the form of four envelopes of two different colors: silver and gold. Trustees knew that if their trustor's outside option was Low, the information would be in one of the two silver envelopes, and the three other envelopes would empty. If their trustor's outside option was High, the information would be in one of the gold envelopes, and the three other envelopes would be empty. Trustees could open (i) a silver envelope, (ii) a gold envelope, or (iii) both a silver envelope and a gold envelope. ${ }^{20}$ By opening a single envelope, trustees can strategically bias their information acquisition to learn only about one of the two signals. In contrast, opening both a silver and a gold envelope maximizes trustees' chances to learn the trustor's actual outside option. The information acquisition procedure is summarized in Figure 2.
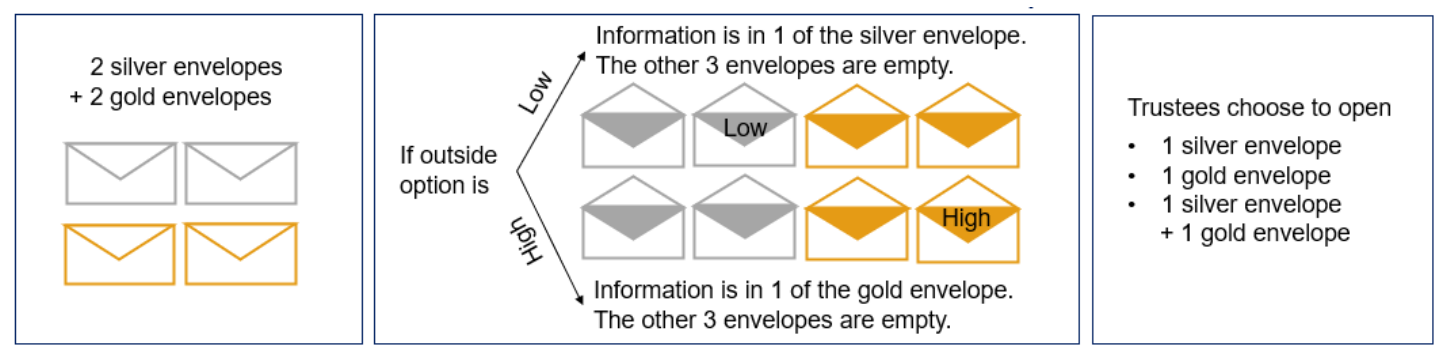

Figure 2: Choosing a source of information

Post-experimental questionnaires. By definition, participants' level of reasoning may affect their responsiveness to our treatment manipulation (as trustees needed to infer their trustor's expectations from their trustor's potential outside options). Hence, we elicited participants level of reasoning using a $2 / 3$ beauty-contest game at the end of the experiment. Participants were asked to indicate a number between 0 and 100, and were rewarded with 100 cents if the number they indicated corresponded to two-third of the mean of the numbers indicated by all participants enrolled in the experiment. We also asked participants to report their age, gender, employment status, annual income and weekly expenditure. Finally, participants were asked to

\footnotetext{
${ }^{20}$ The order of presentation of the envelopes was randomized at the participant level.
} 
rate the clarity of the instructions using a scale from "extremely unclear" to "extremely clear". In addition, we asked trustees to explain their information acquisition decision in a free form format. They were rewarded 50 cents to provide an answer.

Procedures We conducted the experiment online on Amazon MTurk. We recruited a total of 320 participants from the United States of America. ${ }^{21}$ Participation was restricted to individuals over 18 years of age, who completed at least 300 HITs with an approval rate of at least $99 \%$. Participants were randomly allocated the role of trustor or trustee at the beginning of the experiment. Pairs were formed after all participants had completed the experiment. During the experiment, participants could re-read the instructions at any time by clicking on a reminder button at the top of their screen. ${ }^{22}$ Moreover, they had to answer a comprehension questionnaire correctly after the presentation of the instructions in order to proceed. Participants were paid less than 48 hours after the completion of the experiment.

\section{Experimental Hypotheses}

In Section 2, we assumed that a higher trustor's outside option increases both trustors' firstorder beliefs and trustees' second-order belief about the trustor's payoff from choosing In. This is based on the rationale that a profit-maximizing trustor chooses In only if she expects to receive an amount at least equal to the outside option that she foregoes by doing so. ${ }^{23}$

Auxiliary Hypothesis 1. Conditional on choosing In, trustors' first-order beliefs and trustees' second-order beliefs increase with the trustor's outside option.

\footnotetext{
${ }^{21}$ With that sample size, the minimum detectable effect size with statistical power at the recommended .80 level is 0.44 for comparisons of the proportion of each information acquisition strategy between beliefindependent and belief-dependent trustees (Cohen, 2013), which is sufficient to detect an effect of half the magnitude of the one observed in Spiekermann and Weiss (2016).

${ }^{22}$ The screens used in the experiment are provided in Appendix D.

${ }^{23}$ Note that our manipulation of the outside option only implies that the distribution of "rational" beliefs conditional on choosing In has a higher minimum when the outside option is High rather than Low. Yet, it is possible that a trustor's first-order beliefs are constant across the two outside options but still within the range of "rational" beliefs.
} 
If Auxiliary Hypothesis 1 is verified, we can identify trustees' types based on their conditional transfer decisions: non belief-dependent (i.e., their return does not depend on the trustor's expectations), guilt-averse (i.e., their return increases with the trustor's expectations) and reciprocal (i.e., their return decreases with the trustor's expectations). Because we do not observe trustees' guilt sensitivity $\gamma_{i}$ or reciprocity sensitivity $\rho_{i}$, but only their choice $y$ and their beliefs about the trustor's expectations $\Phi_{\omega}$, we follow Dufwenberg et al. (2011) in identifying belief-dependent trustees approximately (rather than exactly). We contend that we can identify sufficiently guilt-averse players through the positive relationship between $y$ and $\Phi_{\omega} \cdot{ }^{24}$ To identify reciprocal trustees, we adopt a similar method. We know that the higher $\Phi_{\omega}$, the less likely $\rho_{i}$ is to exceed the threshold $\frac{2}{110-\Phi_{\omega}}$ above which it implies $y^{*}=200$. Therefore, we can identify reciprocal trustees through the negative relationship between $y$ and $\Phi_{\omega}$. This leads to our second auxiliary hypothesis.

Auxiliary Hypothesis 2. The proportion of trustees identified as having belief-dependent preferences is strictly positive.

Our main research question is to identify whether individuals who exhibit belief-dependent preferences bias their information acquisition strategy in a self-serving way. Belief-dependent preferences can be objective, that is, they depend on the actual state of the world. Participants with such preferences maximise their utility when their return matches the state of the world. Hence, they should open both a silver and a gold envelope, regardless of their belief-dependent motive, as doing so maximise their chances to learn the true state of the world. Yet, belief-dependent preferences can also be subjective, that is, they can depend on individuals' beliefs about the state of the world. In this case, our model predicts differentiated information acquisition strategies depending on the participant's belief-dependent motive. As described in Proposition 4, trustees with subjective belief-dependent preferences should acquire the signal that minimizes the tension between his monetary payoff and his belief-dependent concerns. Hence, a guilt-averse trustee should only seek a Low signal, as doing so gives them the opportunity to learn that the state

\footnotetext{
${ }^{24}$ Remember that $y^{*} \in\left\{0 ; \Phi_{\omega}\right\}$.
} 
of the world is Low, while avoiding to learn that the state is High. Symmetrically, a reciprocal trustee should only seek a High signal, as doing so gives them the opportunity to learn that the state of the world is High, while avoiding to learn that the state is Low. This leads to our two main hypotheses.

Hypothesis 1. Guilt-averse trustees are more likely to open only the silver envelope compared to belief-independent trustees.

Hypothesis 2. Reciprocal trustees are more likely to open only the gold envelope compared to belief-independent trustees.

These hypotheses were pre-registered on AsPredicted. ${ }^{25}$

\section{$5 \quad$ Experimental Results}

In this section, we first evaluate whether beliefs are affected by the outside option manipulation. Then, we classify trustees' according to their type of preferences: belief-independent, guilt-averse or reciprocal. Finally, we assess how these preferences affect the trustees' information acquisition strategy.

\subsection{Are beliefs affected by the outside option manipulation?}

In this section, we assess whether Auxiliary Hypothesis 1 is verified, that is, whether trustors' first-order beliefs and trustees' second-order beliefs about trustors' payoff from choosing In are higher in High game than in the Low game.

Figure 3 displays the combination of beliefs about trustors' expected payoffs from choosing In in the Low game (x-axis) and the High game (y-axis). Beliefs of trustors are presented in the left panel and those of trustees in the right panel. Figure 3 shows that there is a lot of heterogeneity in responsiveness to the outside option manipulation.

\footnotetext{
${ }^{25}$ Link: https://aspredicted.org/blind.php? $\mathrm{x}=9 \mathrm{md} 4 \mathrm{uc}$.
} 


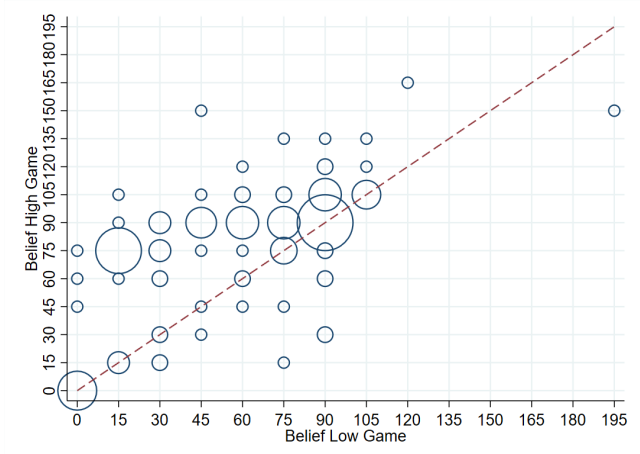

(a) Trustors' first-order beliefs

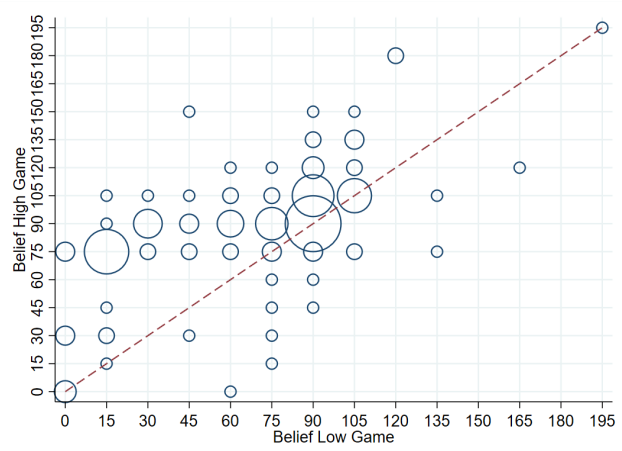

(b) Trustees' second-order beliefs

Figure 3: Distribution of individual beliefs about trustors' expected payoff from In

The majority of participants' beliefs verify Auxiliary Hypothesis 1 . We find that $53.13 \%$ of trustors and $61.25 \%$ of trustees held higher beliefs in the High game than in the Low game (i.e., observations above the 45 degree line). In contrast, $10 \%$ of trustors and $8.13 \%$ of trustees indicated higher beliefs in the Low game than in the high Game (i.e., observations below the 45 degree line), while $28.75 \%$ of trustors and $38.75 \%$ of trustees indicated similar expectations regardless of the game being played (i.e., observations on the 45 degree line). Interestingly, there seems to be a strong focal point around the egalitarian allocation with $50 \%$ of the participants with undifferentiated beliefs indicating beliefs at 90 cents in both games. To test our theoretical predictions, further analyses focus on the sub-sample of trustees who satisfied Auxiliary Hypothesis 1.

Result 1. 53.13\% of trustors' first-order beliefs and 61.25\% of trustees' second-order beliefs are higher when the outside option is High rather than Low.

\subsection{Are trustees motivated by belief-dependent preferences?}

In this section, we classify trustees who satisfy Auxiliary Hypothesis 1 as guilt-averse, reciprocal or belief-independent based on their conditional transfers. Figure 4 displays the combinations of trustees' returns in the Low game (x-axis) and the High game (y-axis). Trustees who returned more in the High than in the Low game are classified as guilt-averse (i.e., observations above the 45 degree line). In contrasts, trustees who returned more in the Low than in the High game are classified as reciprocal (i.e., observations below the 45 degree line). Finally, trustees 
who returned the same amount regardless of the game are classified as belief-independent (i.e., observations on the 45 degree line).

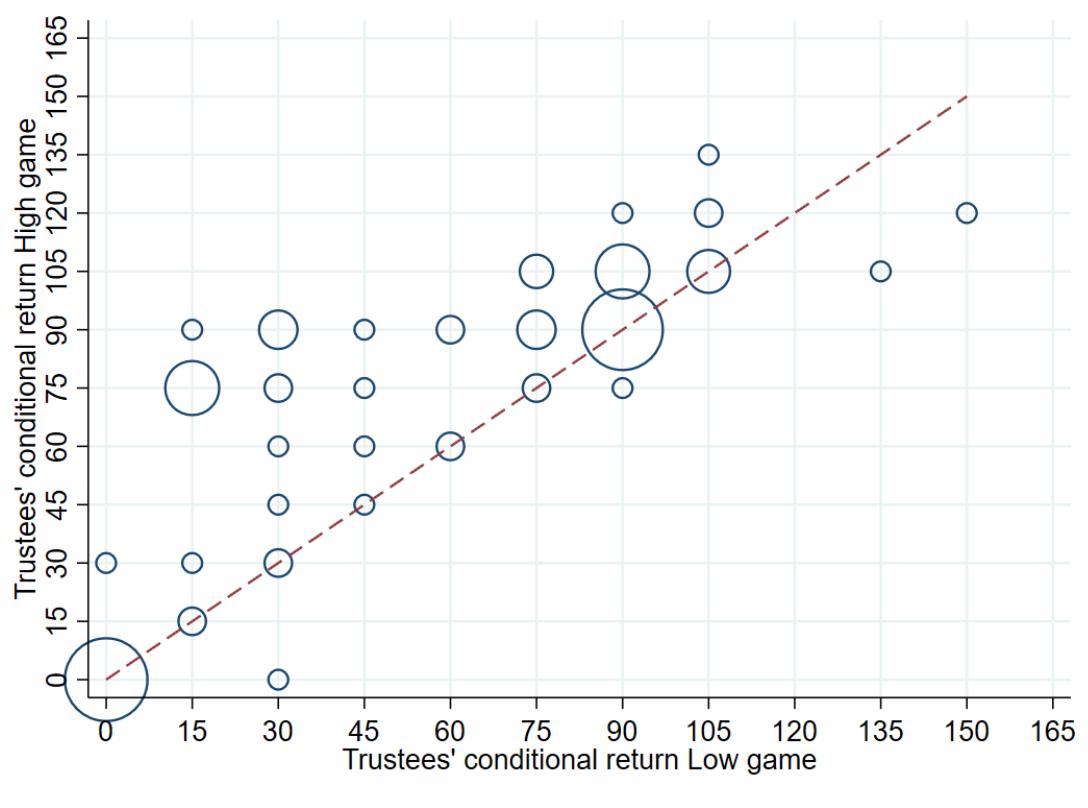

Figure 4: Trustees' return strategies

About half of the trustees can be classified as belief-independent $(52.04 \%, \mathrm{n}=51)$, returning on average 50.00 cents $(\mathrm{se}=6.14)$. This average return hides two focal points where the trustees' payoff is maximized (returning 0 cents) and where equality is maximized (returning 90 cents). We found that $43.88 \%(\mathrm{n}=43)$ of trustees can be classified as guilt-averse. The average amount returned by guilt-averse trustees is 87.91 cents $(\mathrm{se}=3.37)$ in the High game and 53.37 cents $(\mathrm{se}=5.02)$ in the Low game. Only $4.08 \%$ of trustees can be classified as reciprocal $(\mathrm{n}=4)$. The average amount returned by reciprocal trustees is 75 cents $(\mathrm{se}=26.70)$ in the High game and 101.25 cents $(\mathrm{se}=26.95)$ in the Low game (Wilcoxon signed rank test, $p=0.058$ ). These observations yield Result 2 .

Result 2. There is a positive proportion of belief-dependent trustees in our sample: $43.88 \%$ of trustees can be classified as guilt-averse, and $4.08 \%$ of trustees can be classified as reciprocal. 


\subsection{How do belief-based preferences affect information acquisi- tion?}

We now examine whether belief-independent and belief-dependent trustees adopt different information acquisition strategies. As discussed in Section 2, we focus on trustees whose choices revealed a trade-off between their monetary and their belief-dependent motives. This excludes two reciprocal trustees who returned more than 90 (i.e. who cared only about their reciprocal motivation) and one additional reciprocal trustee who indicated that trustors' expected to receive more than 110 conditional on choosing In (i.e., who perceived the trustor as unkind). Because this leaves us with only one reciprocal trustee that satisfies the criteria above, we restrict our analysis of trustees' information acquisition strategies to trustees that we classified as either belief-independent or guilt-averse. ${ }^{26}$

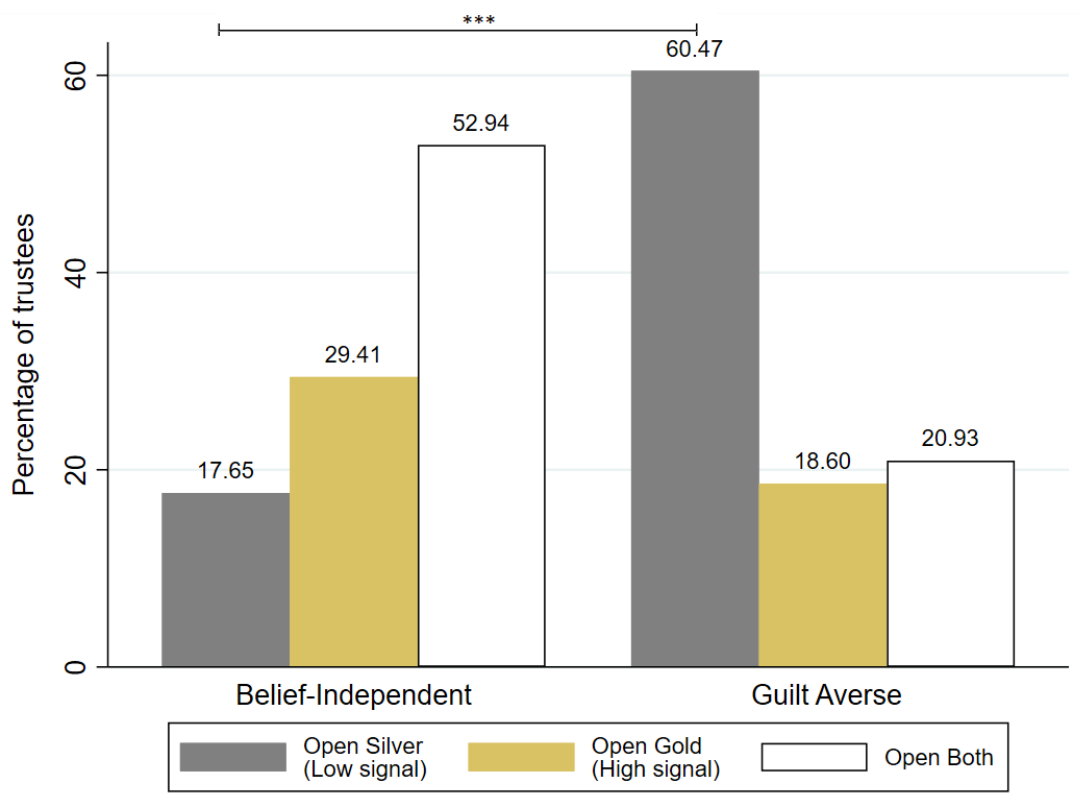

Figure 5: Distribution of information acquisition strategies for belief-independent and guilt-averse trustees.

Figure 5 displays the distribution of information acquisition strategies for belief-independent (left-hand side) and guilt-averse trustees (right-hand side). It shows that the majority of belief-

\footnotetext{
${ }^{26}$ Note that the unique reciprocal trustee with a tension between his/her material and reciprocal motivation chose to acquire a High signal only, which is consistent with subjective preferences.
} 
independent trustees chose to open both envelopes (52.94\%) and they did so significantly more than they would by chance (binomial test, $H 0=0.33, p=0.004$ ). We found that $17.65 \%$ of belief-independent trustees opened a silver envelope only, and $29.41 \%$ opened a gold envelope only. While our model makes no prediction on what belief-independent trustees should do, these results suggest that the default choice in the absence of strategic concerns, is to acquire as much information as possible. ${ }^{27}$ The post-experimental questionnaire allows us to investigate potential explanation for the trustees' information acquisition strategy. It revealed that $75 \%$ of belief-independent trustees who chose to open both envelopes indicated that they did so out of curiosity. $^{28}$

In contrast to belief-independent trustees, the majority of guilt-averse trustees chose to open a silver envelop only (60.46\%) and they did so significantly more than they would by chance (binomial test, $H 0=0.33, p<0.001)$. In addition, the proportion of guilt-averse trustees who chose to open a silver envelope only is significantly higher than the proportion of belief-independent trustees who made the same choice (Pearson's chi-square test, $p<0.001$ ) (Result 3). The results of multinomial logit regressions reported in Table 3 in Appendix corroborate these findings. Altogether, these observations suggest that the majority of guilt-averse trustees exhibit an information acquisition strategy consistent with subjective preferences. In the post-experimental questionnaire, $79.17 \%$ of guilt-averse trustees who chose to open a silver envelope indicated that they did so because it maximized their payoffs. ${ }^{29}$

Result 3. Guilt-averse trustees are more likely to open only the silver envelope compared to belief-independent trustees.

Although our model is agnostic on the relative proportions of the different information acquisition strategies, it is noteworthy that $20.93 \%$ of guilt-averse trustees chose to open both envelopes and $18.60 \%$ opened a gold envelope only. Both of these proportions are significantly lower than

\footnotetext{
${ }^{27}$ Belief-independent trustees earn the same payoff irrespective of what they learn, as their conditional returns are the same regardless of the trustor's outside option.

${ }^{28}$ This result is based on the answers of the 43 out of 51 belief-independent trustees who did provide an answer. The distribution of answers can be found in Table 2 in Appendix.

${ }^{29}$ This result is based on the answers of the 40 out of 43 guilt-averse trustees who did provide an answer.
} 
the proportion of trustees opening a silver envelope only (Wilcoxon signed rank tests: $p=0.004$ and $p=0.002$, respectively). The trustees opening both envelopes displayed a behavior consistent with objective guilt-averse preferences. However, we contend that the proportion of trustees opening a gold envelope only corresponds to behavioral noise. Indeed, Figure 11 in Appendix shows that this share goes down to $5.56 \%$ when excluding trustees who reported that (i) they did not understand that their choice of envelopes was payoff-relevant $(n=6)$ or (ii) the instructions were not "extremely clear" $(\mathrm{n}=24)$.

Table 1: Average marginal effects of monetary incentives on the likelihood of each sampling strategy

\begin{tabular}{lcccccc}
\hline & \multicolumn{2}{c}{ Open Silver } & \multicolumn{2}{c}{ Open Gold } & \multicolumn{2}{c}{ Open both } \\
& $(1)$ & $(2)$ & $(3)$ & $(4)$ & $(5)$ & $(6)$ \\
\hline Return(High) - Return(Low) & 0.003 & 0.004 & -0.000 & 0.000 & -0.003 & -0.004 \\
& $(0.004)$ & $(0.004)$ & $(0.003)$ & $(0.003)$ & $(0.003)$ & $(0.003)$ \\
\hline Ind. controls & No & Yes & No & Yes & No & \multirow{2}{*}{ Yes } \\
\hline Observations & 43 & 43 & 43 & 43 & 43 & \multirow{2}{*}{43} \\
\hline
\end{tabular}

Notes: Table 1 reports the average marginal effects of our multinomial logit model of the difference in conditional returns on the likelihood of a given sampling strategy. Controls include the amount guessed in the beauty contest game and socio-demographic characteristics (age, identifying as a female, annual income, weekly expenditure). The sample is restricted to guilt-averse trustees only. Standard errors are in parentheses. ${ }^{*} p<0.05,{ }^{* *} p<0.01,{ }^{* * *} p<0.001$.

To further investigate the determinants of guilt-averse trustees' information acquisition strategy, we estimate multinomial logit models in which the dependent variable is a categorical variable that summarizes the three information acquisition strategies. The main explanatory variable corresponds to the difference between the amount returned by a guilt-averse trustee when he/she learns that the game is High and the amount returned when he/she learns that the game is Low. We control for participants' age and whether the participant indicated that she identified as a female, as well as participants' annual income and average weekly expenditures. 
The average marginal effects (AME) are displayed in Table 1. We do not find evidence that conditional returns affects trustees' information acquisition strategy. Interestingly, female trustees are significantly more likely to open both envelopes $(A M E=0.207, p=0.035)$, which suggest that female trustees are more likely to hold objective belief-dependent preferences than nonfemale trustees. This is supported by Table 5 in Appendix, which shows no differences in beliefs or conditional return decisions between female and non-female trustees.

In the light of our small sample size, we do not find evidence that guilt-averse trustees with the most money to lose from learning about a specific state of the world are the most likely to engage in self-serving information acquisition strategies.

\section{Discussion and Conclusion}

Other-regarding preferences are prevalent in most human societies. However, the robustness of these preferences tends to be challenged in the presence of uncertainty in their decision environment. For instance, individuals with outcome-based preferences have been shown to exploit uncertainty about the relationship between actions and outcomes to behave more selfishly. In contrast, the literature on belief-dependent preferences has focused on situations where the uncertainty on others' expectations is automatically resolved when the action is implemented. Hence, one can wonder whether individuals with belief-based preferences would be prone to avoid the cost of following their conscience when given the opportunity to do so. In this paper, we investigated whether individuals with belief-dependent preferences select their source of information strategically in order to minimize the tension between their monetary interest and their belief-dependent motive.

We adapted the information acquisition model by Spiekermann and Weiss (2016) to study whether guilt-averse and reciprocal agents strategically acquire information about others' ex- 
pectations. Our model predicts that agents with objective belief-dependent preferences always prefer more information, while agents with subjective belief-dependent preferences strategically seek information that minimizes the tension between their monetary interest and their beliefdependent concern. We then tested our predictions in an online experiment. We designed a modified trust game in which we manipulate trustees' beliefs about trustors' expectations by varying trustors' outside option. We then elicited trustees' preferences by asking them to report their return choices conditionally on the trustors' outside option. Finally, trustees were given the opportunity to acquire information about the trustors' outside option.

We found that about half of trustees could be classified as guilt-averse (44\%). Among these guilt-averse trustees, $60.47 \%$ chose to acquire only the signal that was congruent with their monetary incentives, consistent with our theoretical predictions for subjective preferences. We did not find that individuals with the most differentiated return decisions were more likely to engage in such self-serving information acquisition strategies. Finally, it is worth mentioning that a non-trivial fraction of our sample acquired information in a pattern consistent with objective belief-dependent preferences (20.93\%).

Our main contribution is to show that a majority of individuals bias their information acquisition strategy towards self-serving signals to avoid the expected monetary cost of following their conscience (i.e., implementing the return decision that corresponds to the true state of the world). In the literature on belief-dependent preferences, the uncertainty about others' expectations is typically resolved when actions are implemented (cf. menu method). Our experimental design deviates from this literature by allowing uncertainty about other's expectations either not to be resolved or to be resolved strategically, which is a more realistic information structure. Our findings suggest that previous research have captured an upper bound of the positive impact of belief-dependent preferences on pro-social behavior.

Nonetheless, our paper has some limitations. Both our theoretical model and our experimental design consider the case of a coarse mapping of beliefs, i.e., the belief about the state of the 
world is a step function. If we were to relax this feature and allow for linear beliefs, the optimal choice of a trustee with subjective belief-dependent preferences would be to avoid information altogether, a choice that was not available in our experiment.

In terms of policy implications, it seems that nudging people towards pro-social outcomes can be done through their belief-dependent preferences only if others' expectations cannot be ignored. When others' expectations are uncertain and strategic information search is possible, a majority of belief-dependent individuals seek self-serving information, which eventually leads them to select the payoff-maximizing action without compromising their belief-dependent motives. 


\section{References}

Andreoni, J. and Sanchez, A. (2020). Fooling myself or fooling observers? avoiding social pressures by manipulating perceptions of deservingness of others. Economic Inquiry, 58(1):1233.

Attanasi, G., Battigalli, P., Nagel, R., et al. (2010). Disclosure of belief-dependent preferences in the trust game. In $B Q G T$, pages $51-1$.

Attanasi, G., Rimbaud, C., and Villeval, M. C. (2019). Embezzlement and guilt aversion. Journal of Economic Behavior \& Organization, 167:409-429.

Balafoutas, L. and Fornwagner, H. (2017). The limits of guilt. Journal of the Economic Science Association, 3(2):137-148.

Balafoutas, L. and Sutter, M. (2017). On the nature of guilt aversion: Insights from a new methodology in the dictator game. Journal of Behavioral and Experimental Finance, 13:9-15.

Battigalli, P. and Dufwenberg, M. (2007). Guilt in games. American Economic Review, 97(2):170-176.

Bellemare, C., Sebald, A., and Strobel, M. (2011). Measuring the willingness to pay to avoid guilt: estimation using equilibrium and stated belief models. Journal of Applied Econometrics, 26(3):437-453.

Bellemare, C., Sebald, A., and Suetens, S. (2018). Heterogeneous guilt sensitivities and incentive effects. Experimental Economics, 21(2):316-336.

Bolton, G. E. and Ockenfels, A. (2000). Erc: A theory of equity, reciprocity, and competition. American economic review, 90(1):166-193.

Charness, G. and Dufwenberg, M. (2006). Promises and partnership. Econometrica, 74(6):15791601.

Chen, S., Heese, C., et al. (2020). Motivated information acquisition in social decisions. Technical report, University of Bonn and University of Mannheim, Germany.

Cohen, J. (2013). Statistical power analysis for the behavioral sciences. Academic press.

d'Adda, G., Gao, Y., Golman, R., and Tavoni, M. (2018). It's so hot in here: Information avoidance, moral wiggle room, and high air conditioning usage.

Dana, J., Weber, R. A., and Kuang, J. X. (2007). Exploiting moral wiggle room: experiments demonstrating an illusory preference for fairness. Economic Theory, 33(1):67-80.

Di Tella, R., Perez-Truglia, R., Babino, A., and Sigman, M. (2015). Conveniently upset: Avoiding altruism by distorting beliefs about others' altruism. American Economic Review, 105(11):3416-42.

Ditto, P. H. and Lopez, D. F. (1992). Motivated skepticism: Use of differential decision criteria for preferred and nonpreferred conclusions. Journal of personality and social psychology, 63(4):568. 
Dufwenberg, M. (2002). Marital investments, time consistency and emotions. Journal of Economic Behavior \&3 Organization, 48(1):57-69.

Dufwenberg, M. and Dufwenberg, M. A. (2018). Lies in disguise-a theoretical analysis of cheating. Journal of Economic Theory, 175:248-264.

Dufwenberg, M., Gächter, S., and Hennig-Schmidt, H. (2011). The framing of games and the psychology of play. Games and Economic Behavior, 73(2):459-478.

Dufwenberg, M. and Kirchsteiger, G. (2004). A theory of sequential reciprocity. Games and economic behavior, 47(2):268-298.

Dufwenberg, M. and Kirchsteiger, G. (2019). Modelling kindness. Journal of Economic Behavior 83 Organization, 167:228-234.

Ellingsen, T., Johannesson, M., Tjøtta, S., and Torsvik, G. (2010). Testing guilt aversion. Games and Economic Behavior, 68(1):95-107.

Exley, C. L. (2016). Excusing selfishness in charitable giving: The role of risk. The Review of Economic Studies, 83(2):587-628.

Fehr, E. and Schmidt, K. M. (1999). A theory of fairness, competition, and cooperation. The quarterly journal of economics, 114(3):817-868.

Feiler, L. (2014). Testing models of information avoidance with binary choice dictator games. Journal of Economic Psychology, 45:253-267.

Fong, C. M. and Oberholzer-Gee, F. (2011). Truth in giving: Experimental evidence on the welfare effects of informed giving to the poor. Journal of Public Economics, 95(5-6):436-444.

Forsythe, R., Horowitz, J. L., Savin, N. E., and Sefton, M. (1994). Fairness in simple bargaining experiments. Games and Economic behavior, 6(3):347-369.

Freddi, E. (2019). Do people avoid morally relevant information? evidence from the refugee crisis. Review of Economics and Statistics, pages 1-45.

Friedrichsen, J., Momsen, K., Piasenti, S., et al. (2020). Ignorance, intention and stochastic outcomes. Technical report.

Garcia, T., Massoni, S., and Villeval, M. C. (2020). Ambiguity and excuse-driven behavior in charitable giving. European Economic Review, 124:103412.

Golman, R., Hagmann, D., and Loewenstein, G. (2017). Information avoidance. Journal of Economic Literature, 55(1):96-135.

Grossman, Z. and Van Der Weele, J. J. (2017). Self-image and willful ignorance in social decisions. Journal of the European Economic Association, 15(1):173-217.

Grubiak, K. (2019). Exploring image motivation in promise keeping-an experimental investigation. Technical report, School of Economics, University of East Anglia, Norwich, UK. 
Haisley, E. C. and Weber, R. A. (2010). Self-serving interpretations of ambiguity in otherregarding behavior. Games and economic behavior, 68(2):614-625.

Inderst, R., Khalmetski, K., and Ockenfels, A. (2019). Sharing guilt: How better access to information may backfire. Management Science, 65(7):3322-3336.

Kajackaite, A. (2015). If i close my eyes, nobody will get hurt: The effect of ignorance on performance in a real-effort experiment. Journal of Economic Behavior Es Organization, 116:518-524.

Khalmetski, K. (2016). Testing guilt aversion with an exogenous shift in beliefs. Games and Economic Behavior, 97:110-119.

Khalmetski, K., Ockenfels, A., and Werner, P. (2015). Surprising gifts: Theory and laboratory evidence. Journal of Economic Theory, 159:163-208.

Larson, T. and Capra, C. M. (2009). Exploiting moral wiggle room: Illusory preference for fairness? a comment. Judgment and decision Making, 4(6):467.

Morell, A. (2019). The short arm of guilt-an experiment on group identity and guilt aversion. Journal of Economic Behavior \& Organization, 166:332-345.

Rabin, M. (1995). Moral preferences, moral constraints, and self-serving biases.

Regner, T. (2018). Reciprocity under moral wiggle room: Is it a preference or a constraint? Experimental Economics, 21(4):779-792.

Regner, T. and Matthey, A. (2017). Actions and the self: I give, therefore i am? Jena Economic Research Papers, 2017:018.

Serra-Garcia, M. and Szech, N. (2019). The (in) elasticity of moral ignorance.

Shalvi, S., Soraperra, I., van der Weele, J. J., and Villeval, M.-C. (2019). Shooting the messenger? supply and demand in markets for willful ignorance. Technical report, Tinbergen Institute Discussion Paper.

Smith, M. K., Trivers, R., and von Hippel, W. (2017). Self-deception facilitates interpersonal persuasion. Journal of Economic Psychology, 63:93-101.

Solda, A., Ke, C., Page, L., and Von Hippel, W. (2019). Strategically delusional. Experimental Economics, pages 1-28.

Spiekermann, K. and Weiss, A. (2016). Objective and subjective compliance: A norm-based explanation of 'moral wiggle room'. Games and Economic Behavior, 96:170-183.

Van der Weele, J. J., Kulisa, J., Kosfeld, M., and Friebel, G. (2014). Resisting moral wiggle room: how robust is reciprocal behavior? American economic Journal: microeconomics, $6(3): 256-64$.

Woods, D. and Servátka, M. (2016). Testing psychological forward induction and the updating of beliefs in the lost wallet game. Journal of Economic Psychology, 56:116-125.

Xiao, E. and Bicchieri, C. (2012). Words or deeds? choosing what to know about others. Synthese, 187(1):49-63. 


\section{A Proofs adapted from Spiekermann and Weiss (2016)}

\section{A.1 Proof on the variation of $\hat{u}$ with respect to $\Phi$}

We want to show that $\hat{u}_{g, i}^{\prime}\left(\Phi_{\omega}\right) \leq 0$ for guilt-averse trustees and $\hat{u}_{r, i}^{\prime}\left(\Phi_{\omega}\right) \geq 0$ for reciprocal trustees. According to the envelope theorem, the total derivative at point $y *$ is equal to the following partial derivative:

$$
\begin{aligned}
\hat{u}_{i}^{\prime}(\Phi) & =\left.\frac{\partial}{\partial \Phi} u_{i}(y, \Phi)\right|_{y=y^{*}} \\
& =\frac{\partial}{\partial \Phi}\left[\left(E-y^{*}\right)-f_{i}\left(y^{*}, \Phi\right)\right]
\end{aligned}
$$

For a guilt-averse trustee, it yields the following. Note that, by construction $\Phi_{\omega} \geq y^{*}$, therefore $\max \left\{0,\left(\Phi_{\omega}-y^{*}\right)\right\}=\Phi_{\omega}-y^{*}$.

$$
\begin{aligned}
\hat{u}_{g, i}^{\prime}\left(\Phi_{\omega}\right) & =\frac{\partial}{\partial \Phi_{\omega}}\left[\left(E-y^{*}\right)-\gamma_{i}\left(\Phi_{\omega}-y^{*}\right)\right] \\
& =-\gamma_{i} \leq 0
\end{aligned}
$$

For a reciprocal trustee, it yields the following:

$$
\begin{aligned}
& \hat{u}_{r, i}^{\prime}\left(\Phi_{\omega}\right)=\frac{\partial}{\partial \Phi_{\omega}}\left[\left(E-y^{*}\right)+\rho_{i}\left(\frac{E-90-\Phi_{\omega}}{2}\right)\left(y^{*}-\frac{E}{2}\right)\right] \\
& =\underbrace{-\frac{\rho_{i}}{2}}_{\leq 0} \underbrace{\left(y^{*}-\frac{E}{2}\right)}_{?}
\end{aligned}
$$

As highlighted in Section 2, we focus on the information acquisition of trustees who face a tradeoff between their monetary and belief-dependent motives, which exclude reciprocal trustees who give more than half of their endowment to the trustor: $y>\frac{E}{2}$ (i.e., trustees who only care about their belief-dependent motive). This restriction is consistent with the typical behavior observed in the literature: the meta-study by Johnson and Milsin (2011) on behavior in the trust-game shows that approximately $90 \%$ of trustees return less than half of their endowment. It is also consistent with the behavior observed in our experimental data, where $88.75 \%$ of trustees returned less than half the endowment in the Low game, and $81.25 \%$ in the High game. Restricting our analysis to the case where $y<\frac{E}{2}$, we can conclude that $\hat{u}_{r, i}^{\prime}(\Phi)>0$.

\section{A.2 Proof of Proposition 3}

In this proof to simplify the notation, we denote $E-y$ as $v(y)$.

When acquiring the signal is $S_{L}$, the expected utility of an objective guilt-averse trustee is the weighted sum of the trustee's guilt when the true state is $\omega=L$ and the trustee knows it (with probability $p s$ ), when the true state is $S_{L}$ but the trustee does not know it (with probability 
$p(1-s)$ ), and when the true state is $S_{H}$ (with probability $(1-p)$ ).

$$
\begin{aligned}
E u_{L}= & p s \cdot u_{g, i}\left(y_{L}^{*}, \Phi_{L}\right)+p(1-s) \cdot v\left(y_{U}^{*}, \Phi_{L}\right)-p(1-s) \cdot g_{i}\left(y_{U}^{*}, \Phi_{L}\right) \\
& +(1-p) \cdot v\left(y_{U}^{*}, \Phi_{H}\right)-(1-p) \cdot g_{i}\left(y_{U}^{*}, \Phi_{H}\right) \\
= & p s \cdot u_{g, i}\left(y_{L}^{*}, \Phi_{L}\right)+(1-p s) \cdot v\left(y_{U}^{*}\right)-p(1-s) \cdot g_{i}\left(y_{U}^{*}, \Phi_{L}\right) \\
& -(1-p) \cdot g_{i}\left(y_{U}^{*}, \Phi_{H}\right)
\end{aligned}
$$

Similarly, when acquiring the signal is $S_{L}$, the expected utility of an objective reciprocal trustee is given by the following equation.

$$
\begin{aligned}
E u_{L}= & p s \cdot u_{r, i}\left(y_{L}^{*}, \Phi_{L}\right)+(1-p s) \cdot v\left(y_{U}^{*}\right)+p(1-s) \cdot r_{i}\left(y_{U}^{*}, \Phi_{L}\right) \\
& +(1-p) \cdot r_{i}\left(y_{U}^{*}, \Phi_{H}\right)
\end{aligned}
$$

When acquiring the signal is $S_{H}$, the expected utility of an objective guilt-averse trustee is the weighted sum of the trustee's guilt when the true state is $\omega=H$ and the trustee knows it (with probability $(1-p) s$ ), when the true state is $S_{H}$ but the trustee does not know it (with probability $(1-p)(1-s)$ ), and when the true state is $S_{L}$ (with probability $p$ ).

$$
\begin{aligned}
E u_{H}= & (1-p) s \cdot u_{g, i}\left(y_{H}^{*}, \Phi_{H}\right)+(1-p)(1-s) \cdot v\left(y_{U}^{*}, \Phi_{H}\right) \\
& -(1-p)(1-s) \cdot g_{i}\left(y_{U}^{*}, \Phi_{H}\right)+p \cdot v\left(y_{U}^{*}, \Phi_{L}\right)-p \cdot g_{i}\left(y_{U}^{*}, \Phi_{L}\right) \\
= & (1-p) s \cdot u_{g, i}\left(y_{H}^{*}, \Phi_{H}\right)+(1-s+p s) \cdot v\left(y_{U}^{*}\right)-(1-p)(1-s) \cdot g_{i}\left(y_{U}^{*}, \Phi_{H}\right) \\
& -p \cdot g_{i}\left(y_{U}^{*}, \Phi_{L}\right)
\end{aligned}
$$

Similarly, when acquiring the signal is $S_{H}$, the expected utility of an objective reciprocal trustee is given by the following equation.

$$
\begin{aligned}
E u_{H}= & (1-p) s \cdot u_{r, i}\left(y_{H}^{*}, \Phi_{H}\right)+(1-s+p s) \cdot v\left(y_{U}^{*}\right)+(1-p)(1-s) \cdot r_{i}\left(y_{U}^{*}, \Phi_{H}\right) \\
& +p \cdot r_{i}\left(y_{U}^{*}, \Phi_{L}\right)
\end{aligned}
$$

When acquiring both signals, the expected utility of an objective guilt-averse trustee is the weighted sum of the trustee's guilt when the true state is $\omega=L$ and the trustee knows it (with probability $p s$ ), when the true state is $\omega=H$ and the trustee knows it (with probability $(1-p) s$ ) when the true state is $S_{L}$ but the trustee does not know it (with probability $p(1-s)$ ), and when the true state is $S_{H}$ but the trustee does not know it (with probability $((1-p)(1-s)$ ).

$$
\begin{aligned}
E u_{L H}= & p s \cdot u_{g, i}\left(y_{L}^{*}, \Phi_{L}\right)+(1-p) s \cdot u_{g, i}\left(y_{H}^{*}, \Phi_{H}\right)+p(1-s) \cdot v\left(y_{U}^{*}, \Phi_{L}\right)-p(1-s) \cdot g_{i}\left(y_{U}^{*}, \Phi_{L}\right) \\
& +(1-p)(1-s) \cdot v\left(y_{U}^{*}, \Phi_{H}\right)-(1-p)(1-s) \cdot g_{i}\left(y_{U}^{*}, \Phi_{H}\right) \\
= & p s \cdot u_{g, i}\left(y_{L}^{*}, \Phi_{L}\right)+(1-p) s \cdot u_{g, i}\left(y_{H}^{*}, \Phi_{H}\right)+(1-s) \cdot v\left(y_{U}^{*}\right) \\
& -p(1-s) \cdot g_{i}\left(y_{U}^{*}, \Phi_{L}\right)-(1-p)(1-s) \cdot g_{i}\left(y_{U}^{*}, \Phi_{H}\right)
\end{aligned}
$$

Similarly, when acquiring both signals, the expected utility of an objective reciprocal trustee is given by the following equation.

$$
\begin{aligned}
E u_{L H}= & p s \cdot u_{r, i}\left(y_{L}^{*}, \Phi_{L}\right)+(1-p) s \cdot u_{r, i}\left(y_{H}^{*}, \Phi_{H}\right)+(1-s) \cdot v\left(y_{U}^{*}\right)+p(1-s) \cdot r_{i}\left(y_{U}^{*}, \Phi_{L}\right) \\
& +(1-p)(1-s) \cdot r_{i}\left(y_{U}^{*}, \Phi_{H}\right)
\end{aligned}
$$

We compare the expected utilities of receiving signal $S_{H}\left(E u_{H}\right)$ to receiving both signals 
$\left(E u_{L H}\right)$.

$$
\begin{aligned}
E u_{L H}-E u_{H}= & p s \cdot u_{g, i}\left(y_{L}^{*}, \Phi_{L}\right)+(1-p) s \cdot u_{g, i}\left(y_{H}^{*}, \Phi_{H}\right)+(1-s) \cdot v\left(y_{U}^{*}\right)-p(1-s) \cdot g_{i}\left(y_{U}^{*}, \Phi_{L}\right) \\
& -(1-p)(1-s) \cdot g_{i}\left(y_{U}^{*}, \Phi_{H}\right)-(1-p) s \cdot u_{g, i}\left(y_{H}^{*}, \Phi_{H}\right)-(1-s+p s) \cdot v\left(y_{U}^{*}\right) \\
& +(1-p)(1-s) \cdot g_{i}\left(y_{U}^{*}, \Phi_{H}\right)+p \cdot g_{i}\left(y_{U}^{*}, \Phi_{L}\right) \\
= & p s \cdot\left[u_{g, i}\left(y_{L}^{*}, \Phi_{L}\right)-v\left(y_{U}^{*}\right)+g_{i}\left(y_{U}^{*}, \Phi_{L}\right)\right] \\
= & p s \cdot[\underbrace{u_{g, i}\left(y_{L}^{*}, \Phi_{L}\right)-u_{g, i}\left(y_{U}^{*}, \Phi_{L}\right)}_{>0}]
\end{aligned}
$$

Equation 18 is positive since, given $\Phi_{L}$, utility is maximal at $\hat{u}_{g, i}\left(\Phi_{L}\right)=u_{g, i}\left(y_{L}^{*}, \Phi_{L}\right)$. Using the same reasoning, it yields to the following equation for subjective reciprocal trustees.

$$
E u_{L H}-E u_{H}=p s \cdot[\underbrace{u_{r, i}\left(y_{L}^{*}, \Phi_{L}\right)-u_{r, i}\left(y_{U}^{*}, \Phi_{L}\right)}_{>0}]
$$

We compare the expected utilities of receiving signal $S_{L}\left(E u_{L}\right)$ to receiving both signals $\left(E u_{L H}\right)$.

$$
\begin{aligned}
E u_{L H}-E u_{L}= & p s \cdot u_{g, i}\left(y_{L}^{*}, \Phi_{L}\right)+(1-p) s \cdot u_{g, i}\left(y_{H}^{*}, \Phi_{H}\right)+(1-s) \cdot v\left(y_{U}^{*}\right)-p(1-s) \cdot g_{i}\left(y_{U}^{*}, \Phi_{L}\right) \\
& -(1-p)(1-s) \cdot g_{i}\left(y_{U}^{*}, \Phi_{H}\right)-p s \cdot u_{g, i}\left(y_{L}^{*}, \Phi_{L}\right)-(1-p s) \cdot v\left(y_{U}^{*}\right) \\
& +p(1-s) \cdot g_{i}\left(y_{U}^{*}, \Phi_{L}\right)+(1-p) \cdot g_{i}\left(y_{U}^{*}, \Phi_{H}\right) \\
= & (1-p) s \cdot\left[u_{g, i}\left(y_{H}^{*}, \Phi_{H}\right)-u_{g, i}\left(y_{U}^{*}, \Phi_{H}\right)\right]>0
\end{aligned}
$$

Equation 20 is positive since, given $\Phi_{H}$, utility is maximal at $\hat{u}_{g, i}\left(\Phi_{H}\right)=u_{g, i}\left(y_{H}^{*}, \Phi_{H}\right)$. Using the same reasoning, it yields to the following equation for subjective reciprocal trustees.

$$
E u_{L H}-E u_{L}=(1-p) s \cdot\left[u_{r, i}\left(y_{H}^{*}, \Phi_{H}\right)-u_{r, i}\left(y_{U}^{*}, \Phi_{H}\right)\right]>0
$$

We can conclude that taking both signals is the preferred choice for objective belief-dependent trustees.

\section{A.3 Proof of Proposition 4}

The expected utility of acquiring signal $S_{L}$ for a subjective trustee corresponds to the weighted sum of the trustee's utility when the state is $\omega=L$ and the trustee knows it with probability (with probability $p s$ ), and when the trustee is uncertain about the state (with probability $1-p s$ ).

$$
E u_{L}=p s \cdot \hat{u}_{i}\left(\Phi_{L}\right)+(1-p s) \cdot \hat{u}_{i}\left(\Phi_{U}\right)
$$

Symmetrically, The expected utility of acquiring signal $S_{L}$ for a subjective trustee corresponds to the weighted sum of the trustee's utility when the state is $\omega=L$ and the trustee knows it with probability (with probability $(1-p) s$ ), and when the trustee is uncertain about the state (with probability $1-s+p s$ ).

$$
E u_{H}=(1-p) s \cdot \hat{u}_{i}\left(\Phi_{H}\right)+(1-s+p s) \cdot \hat{u}_{i}\left(\Phi_{U}\right)
$$

Finally, the expected utility of acquiring signal $S_{L}$ for a subjective trustee corresponds to the weighted sum of the trustee's utility when the state is $\omega=L$ and the trustee knows it with prob- 
ability (with probability $p s$ ), when the state is $\omega=L$ and the trustee knows it with probability (with probability $(1-p) s$ ), and when the trustee is uncertain about the state (with probability $1-s)$.

$$
E u_{L H}=p s \cdot \hat{u}_{i}\left(\Phi_{L}\right)+(1-p) s \cdot \hat{u}_{i}\left(\Phi_{H}\right)+(1-s) \cdot \hat{u}_{i}\left(\Phi_{U}\right)
$$

First, we focus on the case of guilt-averse trustees. To conclude from the equations below, recall that (i) since $\Phi_{L}<\Phi_{U}<\Phi_{H}$, it follows that $\hat{u}_{g, i}\left(\Phi_{L}\right)>\hat{u}_{g, i}\left(\Phi_{U}\right)>\hat{u}_{g, i}\left(\Phi_{H}\right)$, and (ii) $p$ and $s \in[0,1]$.

$$
\begin{aligned}
E u_{L}-E u_{H} & =p s \cdot \hat{u}_{g, i}\left(\Phi_{L}\right)+(1-p s) \cdot \hat{u}_{g, i}\left(\Phi_{U}\right)-(1-p) s \cdot \hat{u}_{g, i}\left(\Phi_{H}\right)-(1-s+p s) \cdot \hat{u}_{g, i}\left(\Phi_{U}\right) \\
& =p s \cdot \hat{u}_{g, i}\left(\Phi_{L}\right)+(1-p s-1+s-p s) \cdot \hat{u}_{g, i}\left(\Phi_{U}\right)-(1-p) s \cdot \hat{u}_{g, i}\left(\Phi_{H}\right) \\
& =p s \cdot \underbrace{\left[\hat{u}_{g, i}\left(\Phi_{L}\right)-\hat{u}_{g, i}\left(\Phi_{U}\right)\right]}_{>0}+(1-p) s \cdot \underbrace{\left[\hat{u}_{g, i}\left(\Phi_{U}\right)-\hat{u}_{g, i}\left(\Phi_{H}\right)\right]}_{>0} \\
E u_{L}-E u_{L H} & =p s \cdot \hat{u}_{g, i}\left(\Phi_{L}\right)+(1-p s) \cdot \hat{u}_{g, i}\left(\Phi_{U}\right)-p s \cdot \hat{u}_{g, i}\left(\Phi_{L}\right)-(1-p) s \cdot \hat{u}_{g, i}\left(\Phi_{H}\right)-(1-s) \cdot \hat{u}_{g, i}\left(\Phi_{U}\right) \\
& =(p s-p s) \cdot \hat{u}_{g, i}\left(\Phi_{L}\right)+(1-p s-1+s) \cdot \hat{u}_{g, i}\left(\Phi_{U}\right)-(1-p) s \cdot \hat{u}_{g, i}\left(\Phi_{H}\right) \\
& =s(1-p) \cdot \underbrace{\left[\hat{u}_{g, i}\left(\Phi_{U}\right)-\hat{u}_{g, i}\left(\Phi_{H}\right)\right]}_{>0}>0
\end{aligned}
$$

We can conclude that, under uncertainty, a subjective guilt-averse trustee who follows a coarse mapping, will acquire signal $S_{L}$, but neither signal $S_{H}$ not both signals.

Second, we focus on the case of reciprocal trustees. To conclude from the equations below, recall that (i) since $\Phi_{L}<\Phi_{U}<\Phi_{H}$, it follows that $\hat{u}_{r, i}\left(\Phi_{L}\right)<\hat{u}_{r, i}\left(\Phi_{U}\right)<\hat{u}_{r, i}\left(\Phi_{H}\right)$, and (ii) $p$ and $s \in[0,1]$.

$$
\begin{aligned}
E u_{H}-E u_{L}= & (1-p) s \cdot \hat{u}_{r, i}\left(\Phi_{H}\right)+(1-s+p s) \cdot \hat{u}_{r, i}\left(\Phi_{U}\right)-p s \cdot \hat{u}_{r, i}\left(\Phi_{L}\right)-(1-p s) \cdot \hat{u}_{r, i}\left(\Phi_{U}\right) \\
= & (s-p s) \cdot \hat{u}_{r, i}\left(\Phi_{H}\right)+(1-s+p s-1+p s) \cdot \hat{u}_{r, i}\left(\Phi_{U}\right)-p s \cdot \hat{u}_{r, i}\left(\Phi_{L}\right) \\
= & (s-p s) \cdot \underbrace{\left.\hat{u}_{r, i}\left(\Phi_{H}\right)-\hat{u}_{r, i}\left(\Phi_{U}\right)\right]}_{>0}+p s \cdot \underbrace{\left[\hat{u}_{r, i}\left(\Phi_{U}\right)-\hat{u}_{r, i}\left(\Phi_{L}\right)\right]}_{>0} \\
E u_{H}-E u_{L H}= & (1-p) s \cdot \hat{u}_{r, i}\left(\Phi_{H}\right)+(1-s+p s) \cdot \hat{u}_{r, i}\left(\Phi_{U}\right)-p s \cdot \hat{u}_{r, i}\left(\Phi_{L}\right) \\
& -(1-p) s \cdot \hat{u}_{r, i}\left(\Phi_{H}\right)-(1-s) \cdot \hat{u}_{r, i}\left(\Phi_{U}\right) \\
= & (1-s+p s-1+s) \cdot \hat{u}_{r, i}\left(\Phi_{U}\right)-p s \cdot \hat{u}_{r, i}\left(\Phi_{L}\right) \\
= & p s \cdot \underbrace{\left[\hat{u}_{r, i}\left(\Phi_{U}\right)-\hat{u}_{r, i}\left(\Phi_{L}\right)\right]}_{>0}
\end{aligned}
$$

We can conclude that, under uncertainty, a subjective reciprocal trustee who follows a coarse mapping, will acquire signal $S_{H}$, but neither signal $S_{L}$ not both signals. 


\section{B Additional Results}

\section{B.1 Aggregated beliefs}

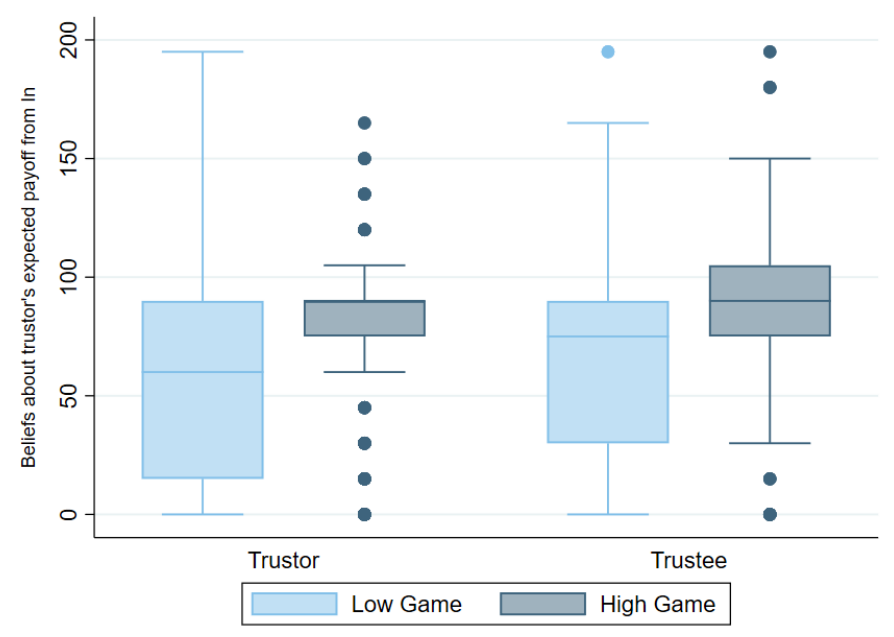

Figure 6: Distribution of trustors and trustees' beliefs about trustors' payoff from In.

Figure 6 shows that the trustors' median belief is lower in the Low game (median $=60$ cents; interquartile range $=75)^{30}$ than in the High game $($ med $=90$ cents; iqr $=15)$. This difference is significant at the $0.01 \%$ level (Wilcoxon rank-sum test, $p<0.001$ ). ${ }^{31}$ Similarly, the trustees' median belief about trustors' belief is lower in the Low game (med $=75$ cents; iqr $=60$ ) than in the High game (med $=90$ cents; iqr $=30$ ). This difference is also significant at the $0.01 \%$ level (Wilcoxon signed rank test, $p<0.001$ ).

\section{B.2 Trustor's behavior}

We showed in Section 5.1 that trustor's expect to receive more from the trustees when their outside option is high rather than low. Consistent with Equation 1, 85.45\% of trustors who choose to go In expects to receive more than their outside option. Moreover, the share of trustees choosing In is lower when the outside option is High (51.85\%) rather than Low $(86.08 \%)$ (chi-square test, $p<0.001$ ).

\section{B.3 Non Classified trustees' behavior}

In the main text analyses, we focus on the behavior of trustees who satisfy Auxiliary Hypothesis 1, that is, trustees who hold higher second-order beliefs when the outside option is High rather than Low. In this section, we describe the behavior of trustees who do not satisfy Auxiliary Hypothesis 1. 28.75\% ( $\mathrm{n}=46)$ of trustees hold the same second-order beliefs regardless of the trustor's outside option. $10 \%$ of trustees $(n=16)$ hold higher second-order beliefs when the

\footnotetext{
${ }^{30}$ Respectively med and iqr, hereafter.

${ }^{31}$ All p-values are two-sided.
} 
trustor's outside option is Low rather than High.

Figure 7 displays the combinations of trustees' returns in the Low game (x-axis) and the High game (y-axis) for trustees with undifferentiated beliefs (in red) and trustees with higher secondorder beliefs when the trustor's outside option is Low rather than High (in blue). In both cases, trustees' return strategies is consistent with their beliefs.

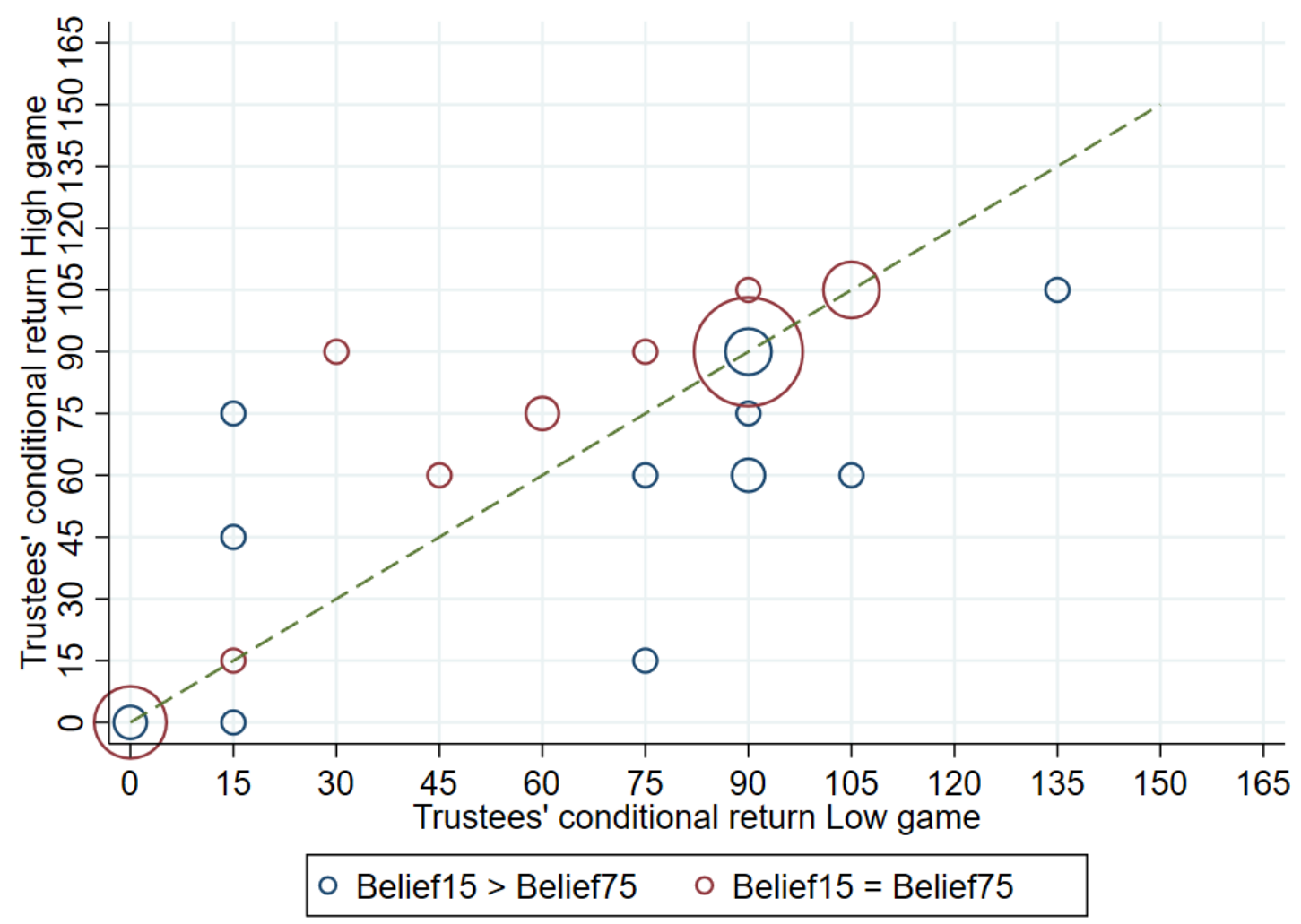

Figure 7: Return strategies of trustees with undifferentiated beliefs (in red) and with higher second-order beliefs when the trustor's outside option is Low rather than High (in blue).

Figure 8 displays the information acquisition strategy of trustees with undifferentiated beliefs (panel (a)) and trustees with higher beliefs in the Low game (panel (b)), separated by conditional return strategies. The majority of trustees with undifferentiated beliefs chose to open both envelopes, regardless of their conditional returns. 40 of these trustees returned the same in both games and $62.50 \%$ of them chose to acquire both envelopes. The remaining 6 returned more in the high game and $50 \%$ of them chose to open both envelopes. Turning to trustees who hold higher beliefs in the Low game, 8 of them returned more in the Low game, 6 of them returned the same in both games and 2 of them returned more in the High game. 


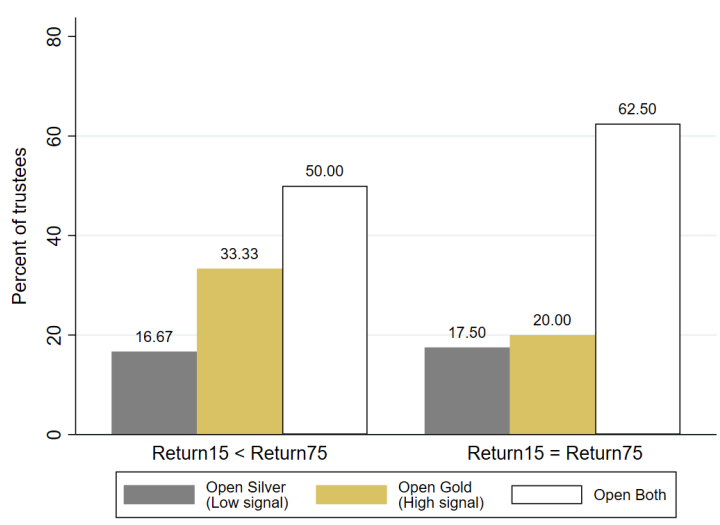

(a) Trustees with undifferentiated beliefs.

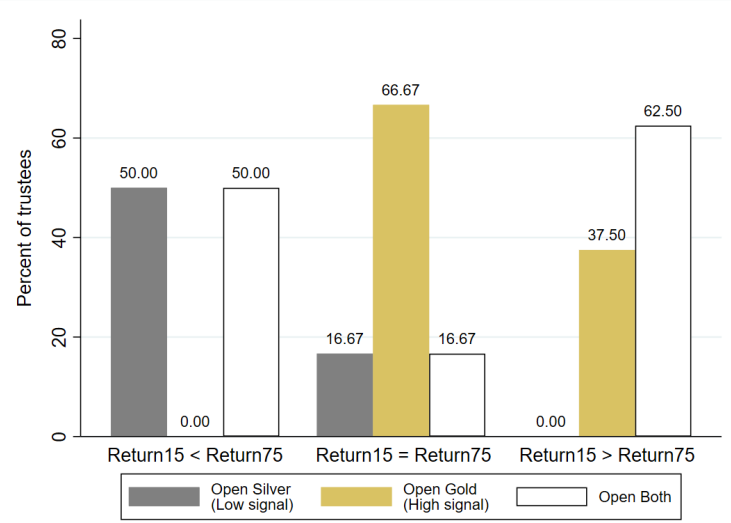

(b) Trustees with higher beliefs in the Low game.

Figure 8: Information acquisition strategy.

\section{B.4 Trustees' justification of their sampling strategies}

We classified the participants' justification of their sampling strategies in four categories (excluding 11 trustees who did not fill in this optional question). The first category pools the trustees who made their choice out of curiosity, e.g., "I was just curious to see if I would find a 15 or 75". Second, we grouped together participants who mentioned their intention to maximize their payoff, e.g., "I chose to open 1 silver envelope hoping it would contain a 15 and then I would maximize my earnings". In the third category, we pooled the participants who reported having made their choice at random, e.g., "I chose 1 envelope honestly just based on feeling". The last category contains answers that we could not classify in the other three categories.

Table 2: Trustees' justification of their sampling strategies

(a) Belief-independent trustees

\begin{tabular}{lccccc}
\hline & Curiosity & Payoff & Random & Other & Total (n) \\
\hline Open Silver & $12.50 \%$ & $25.00 \%$ & $50.00 \%$ & $12.50 \%$ & 8 \\
Open Gold & $36.36 \%$ & $9.09 \%$ & $36.36 \%$ & $18.18 \%$ & 11 \\
Open Both & $62.50 \%$ & $4.17 \%$ & $20.83 \%$ & $12.50 \%$ & 24 \\
\hline
\end{tabular}

(b) Guilt averse trustees

\begin{tabular}{lccccc}
\hline & Curiosity & Payoff & Random & Other & Total (n) \\
\hline Open Silver & $4.17 \%$ & $79.17 \%$ & $4.17 \%$ & $12.50 \%$ & 24 \\
Open Gold & $12.50 \%$ & $37.50 \%$ & $12.50 \%$ & $37.50 \%$ & 8 \\
Open Both & $75.00 \%$ & $12.50 \%$ & $0.00 \%$ & $12.50 \%$ & 8 \\
\hline
\end{tabular}

(c) Reciprocal trustees

\begin{tabular}{cccccc}
\hline & Curiosity & Payoff & Random & Other & Total (n) \\
\hline Open Gold & $0.00 \%$ & $25.00 \%$ & $0.00 \%$ & $75.00 \%$ & 4 \\
\hline
\end{tabular}


Table $2 \mathrm{a}$ shows that when opening one envelope only, the majority of belief-dependent trustees choose at random; while they are motivated by curiosity when they open both envelopes. Table $2 \mathrm{~b}$ shows that the majority opened a silver envelope to maximize their payoff, while they opened both envelope to satisfy their curiosity.

\section{B.5 Trustees' likelihood of having a given sampling strategy}

Table 3 reports the average marginal effect of a multinomial logit model using a categorical variable equals to 0 if the trustee opened a silver envelope only, 1 if the trustee opened a gold envelop only and 2 if the trustee opened both a silver and a gold envelopes as the dependent variable. Regressors include a dummy variable equal to 1 if the trustee is guilt-averse, and 0 if the trustee is belief-independent. Guilt-averse trustees are more likely to open a silver envelope and less likely to open both envelopes than belief-independent trustees and the results are significant at the $0.1 \%$ level. These results are robust to the inclusion of individual controls.

Table 3: Average marginal effects of preferences types on the likelihood of each sampling strategy

\begin{tabular}{lcccccc}
\hline & \multicolumn{2}{c}{ Open Silver } & \multicolumn{2}{c}{ Open Gold } & \multicolumn{2}{c}{ Open both } \\
\hline Belief-independent & Ref. & Ref. & Ref. & Ref. & Ref. & Ref. \\
Guilt averse & $0.428^{* * *}$ & $0.453^{* * *}$ & -0.108 & -0.105 & $-0.320^{* * *}$ & $-0.348^{* * *}$ \\
& $(0.092)$ & $(0.086)$ & $(0.087)$ & $(0.085)$ & $(0.093)$ & $(0.085)$ \\
\hline Ind. controls & No & Yes & No & Yes & No & Yes \\
\hline Observations & 94 & 94 & 94 & 94 & 94 & 94 \\
\hline
\end{tabular}

Notes: This Table reports the average marginal effects estimated by Multinomial Logit models. Individual controls include the amount guessed in the beauty contest game, and socio-demographic characteristics (age, gender, annual income, weekly expenditure). Standard errors are in parentheses. ${ }^{*} p<0.05,{ }^{* *} p<0.01,{ }^{* * *} p<0.001$.

To investigate the driver of differences in trustee's information acquisition strategy, we replicate Table 1 from the main text after including belief-independent subjects.

Table 4: Average marginal effects of monetary incentives on the likelihood of each sampling strategy

\begin{tabular}{lcccccc}
\hline & \multicolumn{2}{c}{ Open Silver } & \multicolumn{2}{c}{ Open Gold } & \multicolumn{2}{c}{ Open both } \\
& $(1)$ & $(2)$ & $(3)$ & $(4)$ & $(5)$ & $(6)$ \\
\hline Return(High) - Return(Low) & $0.008^{* * *}$ & $0.009^{* * *}$ & -0.001 & -0.000 & $-0.007^{* *}$ & $-0.009^{* * *}$ \\
& $(0.002)$ & $(0.002)$ & $(0.002)$ & $(0.002)$ & $(0.003)$ & $(0.003)$ \\
\hline Ind. controls & No & Yes & No & Yes & No & Yes \\
\hline Observations & 94 & 94 & 94 & 94 & 94 & 94 \\
\hline
\end{tabular}

Notes: Table 4 reports the average marginal effects of our multinomial logit model of the difference in conditional returns on the likelihood of a given sampling strategy. Controls include the amount guessed in the beauty contest game and socio-demographic characteristics (age, identifying as a female, annual income, weekly expenditure). Standard errors are in parentheses. ${ }^{*} p<0.05,{ }^{* *} p<0.01,{ }^{* * *}$ $p<0.001$. 
The average marginal effects (AME) are displayed in Table 4. We found that an increase in 10 cents in the difference in conditional returns increases the likelihood to open a silver envelope by up to 9 percentage points (columns (1) and (2)), and decreases the likelihood to open a gold envelope by up to 9 percentage points (columns (5) and (6)). These findings show that individuals who have the most money to lose from learning about a specific state of the world, are also the ones who are the most likely to engage in self-serving information acquisition strategies.

In addition, we replicate the effect from Table 1 that female trustees are significantly more likely to open both envelopes $(A M E=0.244, p=0.007)$ and we also find that they are less likely to open the silver envelope only $(A M E=-0.217 ; p=0.025)$. These findings suggest that female trustees are more likely to hold objective belief-dependent preferences than non-female trustees.

\section{B.6 Determinants of beliefs, returns and preference type.}

To investigate the determinants of participants' beliefs, we estimated a linear regression of the difference in beliefs for both trustors and trustees on participants' individual characteristics. The OLS coefficients are displayed in columns (1) and (2) in Table Table 5, respectively. We find that an increase in the perceived clarity of the instructions increases trustor's sensitivity to our treatment manipulation $(p=0.038)$, but not trustees'. Surprisingly, we find no effect of participants' guess in the beauty contest on their sensitivity to the treatment manipulation ( $p$ $=0.557$ and $p=0.536)$.

In addition, we investigate the determinants of trustees' difference in conditional return choices. To do so, we estimated a linear regression of the difference in conditional returns on trustees' individual characteristics. The OLS coefficients are displayed in column (3). We find no effect of trustees' individual characteristics on their conditional return choices.

Finally, we investigate the determinants of trustees' preference type. To do so, we estimated logit regression of the likelihood of having belief-independent or guilt-averse preferences on trustees' individual characteristics. The average marginal effects are displayed in columns (4) and (5), respectively. We find no effect of trustees' individual characteristics on their preference type. 
Table 5: Determinants of participants' beliefs, trustees' conditional return decisions and preferences type.

\begin{tabular}{|c|c|c|c|c|c|}
\hline Dep. var: & $\begin{array}{c}\text { Diff. belief } \\
\text { trustors } \\
(1)\end{array}$ & $\begin{array}{c}\text { Diff. belief } \\
\text { trustees } \\
(2)\end{array}$ & $\begin{array}{c}\text { Diff. return } \\
\text { trustees } \\
(3)\end{array}$ & $\begin{array}{c}\text { Types } \\
\text { Belief Ind. } \\
(4)\end{array}$ & $\begin{array}{l}\text { Trustees } \\
\text { Guilt-averse } \\
(5)\end{array}$ \\
\hline Level of reasoning & $\begin{array}{c}0.078 \\
(0.133)\end{array}$ & $\begin{array}{c}-0.077 \\
(0.125)\end{array}$ & $\begin{array}{c}0.141 \\
(0.135)\end{array}$ & $\begin{array}{c}0.001 \\
(0.003)\end{array}$ & $\begin{array}{c}-0.002 \\
(0.003)\end{array}$ \\
\hline Female & $\begin{array}{l}-2.502 \\
(4.933)\end{array}$ & $\begin{array}{c}5.807 \\
(5.198)\end{array}$ & $\begin{array}{c}1.464 \\
(5.169)\end{array}$ & $\begin{array}{c}-0.051 \\
(0.112)\end{array}$ & $\begin{array}{c}0.019 \\
(0.111)\end{array}$ \\
\hline Age & $\begin{array}{l}-0.226 \\
(0.209)\end{array}$ & $\begin{array}{l}-0.321 \\
(0.212)\end{array}$ & $\begin{array}{l}-0.106 \\
(0.238)\end{array}$ & $\begin{array}{c}0.008 \\
(0.005)\end{array}$ & $\begin{array}{l}-0.005 \\
(0.005)\end{array}$ \\
\hline Annual income & $\begin{array}{c}0.306 \\
(1.975)\end{array}$ & $\begin{array}{l}-1.551 \\
(1.957)\end{array}$ & $\begin{array}{c}0.226 \\
(1.986)\end{array}$ & $\begin{array}{l}0.0108 \\
(0.043)\end{array}$ & $\begin{array}{l}-0.003 \\
(0.042)\end{array}$ \\
\hline Weekly expenditure & $\begin{array}{l}-4.128 \\
(3.629)\end{array}$ & $\begin{array}{c}6.009 \\
(3.277)\end{array}$ & $\begin{array}{l}-0.315 \\
(3.263)\end{array}$ & $\begin{array}{c}0.002 \\
(0.070)\end{array}$ & $\begin{array}{l}-0.016 \\
(0.069)\end{array}$ \\
\hline Clarity instructions & $\begin{array}{l}8.619^{*} \\
(4.114)\end{array}$ & $\begin{array}{c}2.721 \\
(3.621)\end{array}$ & $\begin{array}{l}-2.137 \\
(3.771)\end{array}$ & $\begin{array}{c}0.122 \\
(0.083)\end{array}$ & $\begin{array}{c}-0.110 \\
(0.081)\end{array}$ \\
\hline Constant & $\begin{array}{c}42.19^{* * *} \\
(13.38)\end{array}$ & $\begin{array}{l}31.67^{*} \\
(14.17)\end{array}$ & $\begin{array}{c}21.79 \\
(14.34)\end{array}$ & - & - \\
\hline Observations & 160 & 160 & 98 & 98 & 98 \\
\hline
\end{tabular}

Notes: Table Table 5 displays the OLS coefficients of participants' individual characteristics on trustors' (column (1)) and trustees' (column (2)) differences in beliefs between the Low and the High game, trustees' differences in return between the Low and the High game (column (3)), as well as the marginal effect from a logit regression of trustees' individual characteristics on their preference type (columns (5) and (6)). Standard errors are in parentheses. ${ }^{*} p<0.05,{ }^{* *} p<0.01,{ }^{* * *} p<0.001$.

\section{Robustness checks Restricted sample}

We pre-registered that we will verify the robustness of our findings by excluding from the analyses participants who indicated in the post-experimental questionnaire that (i) the instructions were not extremely clear or that (ii) the had trouble understanding the instructions.

59 trustors and 81 trustees indicated that the instructions were not extremely clear $(43.75 \%$ of participants). In addition, 13 trustees indicated that they encountered comprehension problem with the instructions while indicating that the instructions were extremely clear $(4.06 \%$ of participants). In the following section, we excluded these participants from the analyses. 


\section{C.1 Are beliefs affected by the outside option manipulation?}

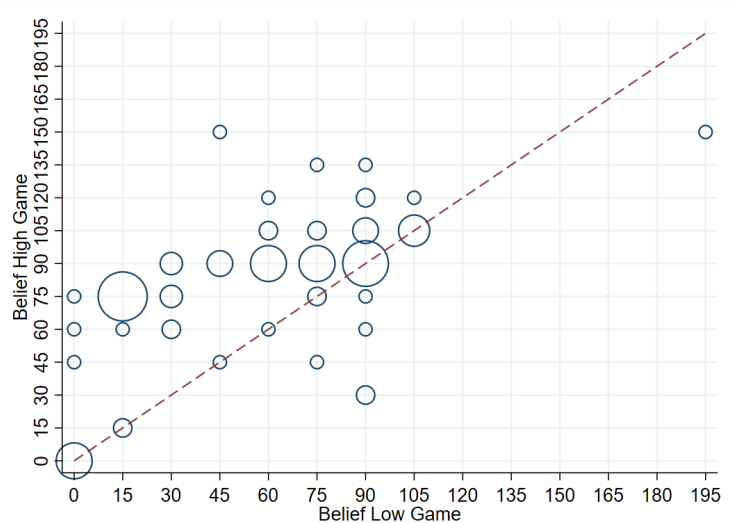

(a) Trustors' first-order beliefs

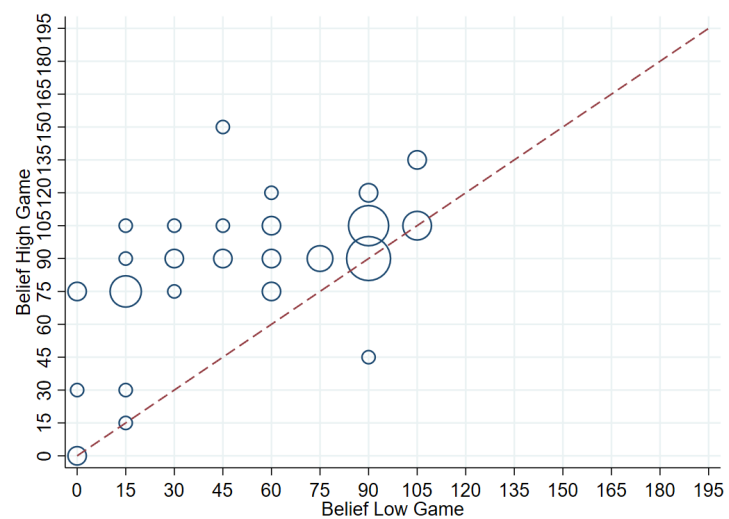

(b) Trustees' second-order beliefs

Figure 9: Distribution of individual beliefs about trustors' expected payoff from In

The proportion of participants who verifies Auxiliary Hypothesis 1 increases slightly. $62 \%$ (vs. $53.13 \%$ ) of trustors and $68.18 \%$ (vs. $61.25 \%$ ) of trustees hold higher beliefs in the High game than in the Low game. In contrast, $5.94 \%$ (vs. 10\%) of trustors and $1.52 \%$ (vs. 8.13\%) of trustees indicated higher beliefs in the Low game than in the high Game, while 32.67\% (vs. 28.75\%) of trustors and $30.30 \%$ (vs. 38.75\%) of trustees indicated similar expectations regardless of the game being played. Overall, Result 1 is not affected by participants comprehension of the experimental instructions.

\section{C.2 Are trustees motivated by belief-dependent preferences?}

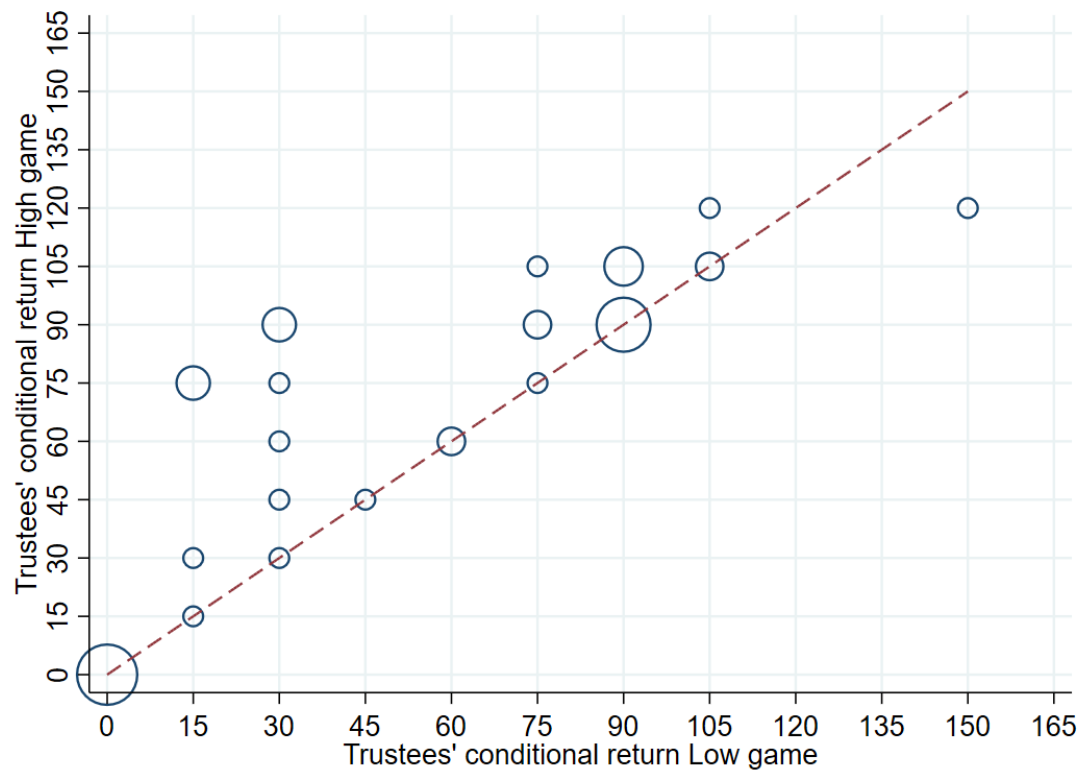

Figure 10: Trustees' return strategies 
$40 \%$ ( $n=18$; vs. $43.88 \%, n=43$ ) of trustees can be classified as guilt-averse. Only one trustee can be classified as reciprocal (vs. $4.08 \%, \mathrm{n}=4$ ). Result 2 is not affected by participants comprehension of the experimental instructions.

\section{C.3 How do belief-based preferences affect information acquisi- tion}

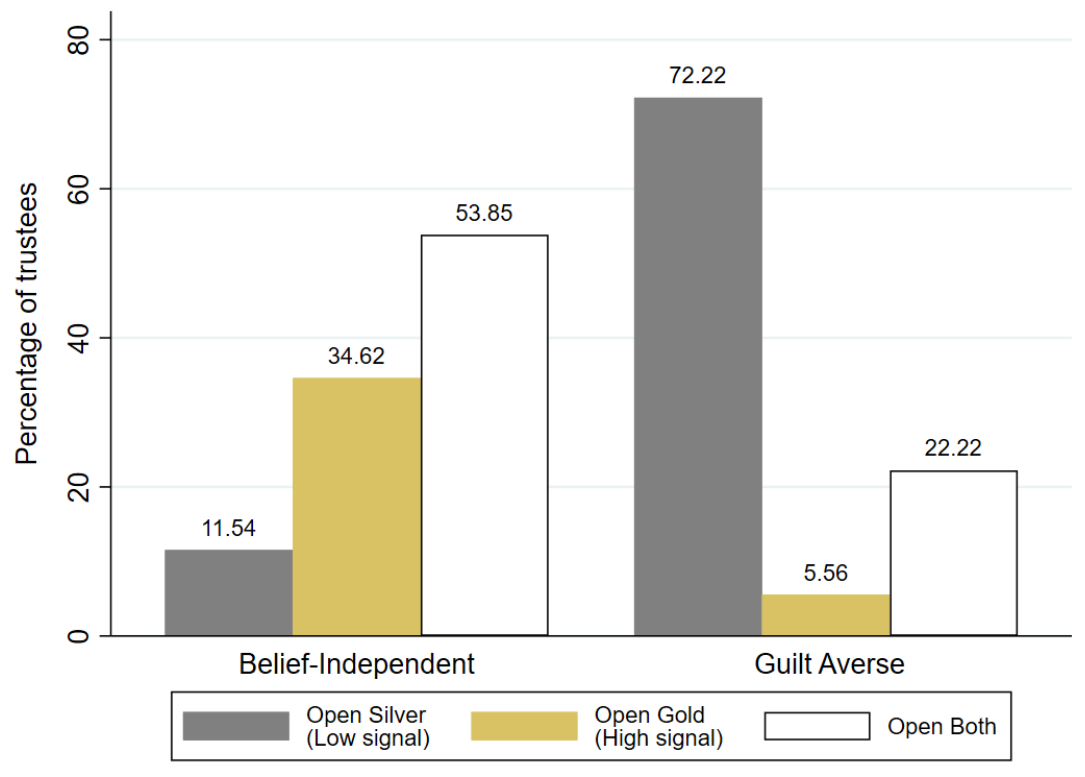

Figure 11: Information acquisition strategy. 


\section{Screens from the online experiment}

\section{D.1 Trustors' screens}

\section{Thank you for participating in this study!}

You are now participating in the study.

This study should take about 5 minutes.

This study is composed of two parts. In each part, you will be asked to make some decisions and answer some questions about your decisions.

You will receive a fixed payment of $25 \mathrm{c}$ for participating in this study and a fixed payment of $25 \mathrm{c}$ for completing this study. In addition, you will earn a bonus payment based on your choices and answers during this study.

You should complete this study all at once. If you log out of the experiment by closing your browser you will not be able to log in back later.

OK

\section{Part 1: Instructions}

All payments in this part are bonus payments, they do not include your fixed payment.

In this part of the study, you can have one of two following roles: Participant A or Participant B.

You have been randomly selected to be Participant $\mathbf{A}$.

You will be matched with a fellow Mturk worker who has been randomly selected to be Participant B.

Your role is to choose between two options (orange or green) that have different consequences on both your earnings and the earnings of Participant $B$.

Before you make a decision, the computer program randomly draws a ball from an urn containing ten balls. Out of these ten balls, five are marked with the number 15 and five are marked with the number 75 .

The number marked on the ball determines your earnings in the orange option.

- If the number on the ball is 15 , you earn $15 \phi$.

- If the number on the ball is 75 , you earn $75 \phi$.

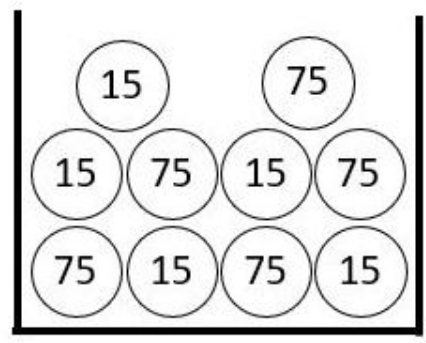

Participant B knows the consequences of the number marked on the ball on your earnings.

More details on the consequences of the two options (orange or green) are given on the next screen 


\section{Part 1: Instructions}

The consequences of your choice of color are explained below.

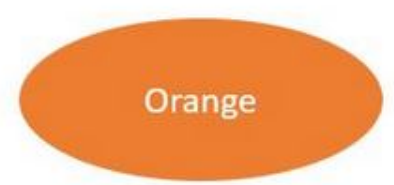

If you choose the orange button, the amount you earn depends on the number on the ball. If the ball is marked with 15 , you earn $15 \%$. If the ball is marked with 75 , you earn $75 \varnothing$. Participant B earns $90 \varnothing$, regardless of the number marked on the ball.

Participant B knows the orange button yields fixed earnings while the green button leaves him/her to decide on how to allocate $200 \mathrm{c}$.

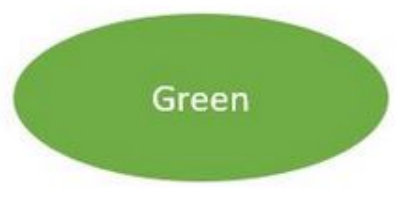

If you choose the green button, you entrust Participant B with $200 \mathrm{c}$ to allocate between the two of you, regardless of the number marked on the ball. 


\section{Part 1: Comprehension Questionnaire}

Click to remind me of the instructions

To make sure that the instructions are clear, please answer the following questions. If you have a doubt about the instructions, click on the button at the top of your screen.

Suppose that you choose the green button, and that Participant B chooses to send you $60 \mathrm{c}$.

1) How much do you earn from this decision?

c

2) How much does Participant B earn from this decision?

Suppose that you choose the orange button.

3) How much do you earn from this decision if the number on the ball is 15 ?

c

4) How much do you earn from this decision if the number on the ball is 75 ?

c

5) How much does Participant B earn from this decision? 


\section{Part 1: Guess Participant B's decision}

\section{Click to remind me of the instructions}

You now have the opportunity to earn an additional $50 \notin$ if you make a correct guess.

If you choose the green button, Participant B decides how to allocate $200 \mathrm{c}$ between the two of you (by increments of 15 ) . We would like to know how much you expect Participant B to send you in this case.

Participant B decides how to allocate $200 \mathrm{c}$ between the two of you, assuming that you choose the green button. Your answer will be compared with Participant B's decision. If you guess the amount correctly (plus or minus $15 c$ ), you will earn $50 \varnothing$ in addition to your other earnings.

If the number on the ball is 15 , you have to give up 15c to let Participant B decide the final earnings (green button). How much do you expect Participant B to send you in this case?

-- select an option -- $\vee c$

If the number on the ball is 75 , you have to give up $75 \dot{c}$ to let Participant B decide the final earnings (green button). How much do you expect Participant B to send you in this case?

-- select an option -- $\vee c$

\section{Part 1: Your decision}

The computer program randomly selected a ball marked with the number 15 .

You reported that you expect that Participant B will send you 30 $\mathrm{c}$ if you choose green .

Click on one of the buttons below to make a decision:

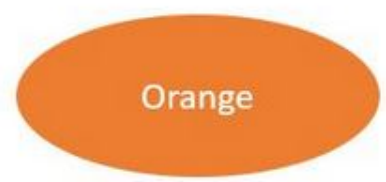

If you choose the orange button, you earn $15 \phi$ and Participant B earns 90c.

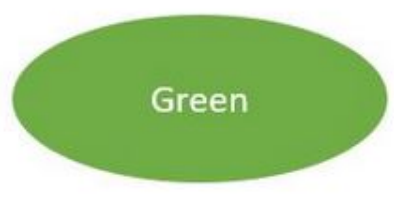

If you choose the green button, you entrust Participant B with $200 \&$ to allocate between the two of you. 


\section{Part 2}

All payments in this part are bonus payments, they do not include your fixed payment.

In this part of the study, you and all the other participants to the study must guess a number between 0 and 100 (inclusive). The participant whose chosen number is the closest to the two-third of the mean of all chosen numbers earns $100 \notin$. In case of a tie, the participant who earns the $100 \varnothing$ will be chosen at random by the computer program.

What is your chosen number?

\section{OK}

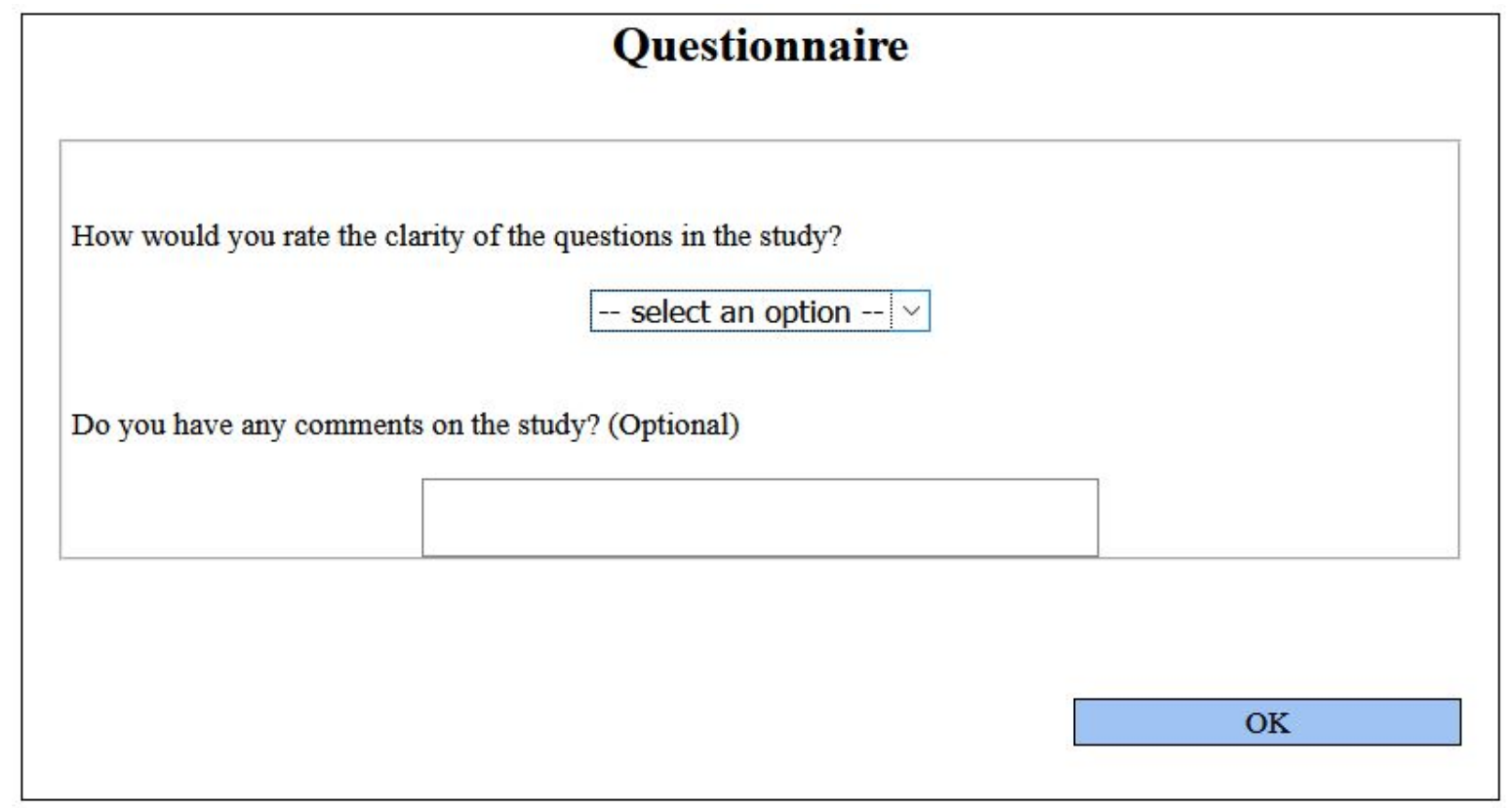




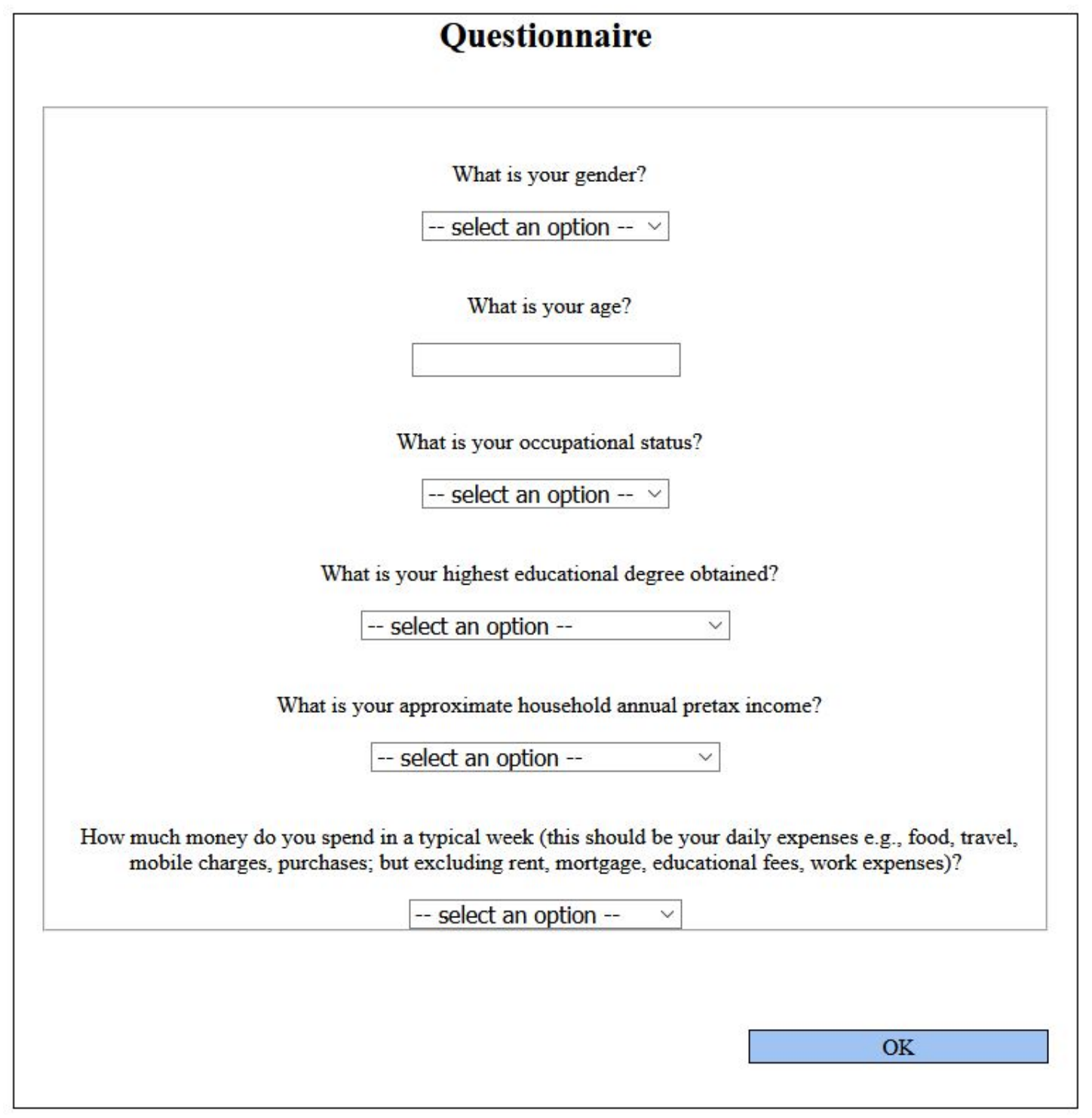




\section{D.2 Trustees' screens}

\section{Thank you in participating to this study!}

You are now participating in the study.

This study should take about 15 minutes.

This study is composed of two parts. In each part, you will be asked to make some decisions and answer some questions about your decisions.

You will receive a fixed payment of $25 \phi$ for participating in the study and of $50 \notin$ for completing this study. In addition, you will earn a bonus payment based on your choices and answers during this study.

You should complete this study all at once. If you log out of the experiment by closing your browser you will not be able to log in back later.

\section{OK}

\section{Part 1: Instructions}

All payments in this part are bonus payments, they do not include your fixed payment.

In this part of the study, you can have one of two following roles: Participant A or Participant B.

You have been randomly selected to be Participant B.

You will be matched with a fellow Mturk worker who has been randomly selected to be Participant A.

The role of Participant A is to choose between two options (orange or green) that have different consequences on both your earnings and the earnings of Participant A.

Before Participant A makes a decision, the computer program randomly draws a ball from an urn containing ten balls. Out of these ten balls, five are marked with the number 15 and five are marked with the number 75 . The number marked on the ball determines the earnings of Participant $\mathrm{A}$ in the orange option.

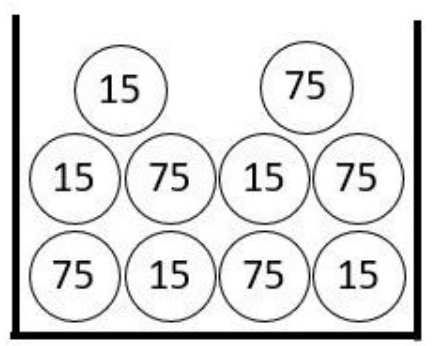

More details on the consequences of the two options (orange or green) are given on the next screen. 


\section{Part 1: Instructions}

Participant A's options are presented below.

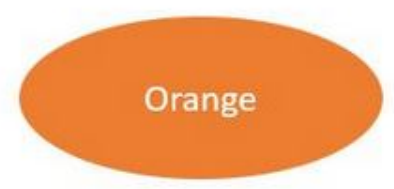

If Participant A chooses orange, you have no choice to make. The earnings of Participant $A$ are determined by the number marked on the ball. If the ball is marked with 15 , Participant A earns $15 \%$. If the ball is marked with 75, Participant A earns $75 c$. You earn $90 \%$, regardless of the number marked on the ball.

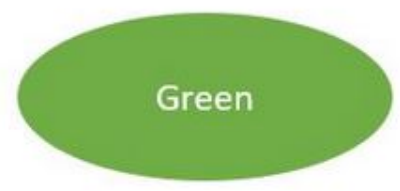

If Participant $\mathrm{A}$ chooses green, you have to make a choice that impacts both of your earnings. Participant A entrusts you with $200 \phi$ and you choose how to allocate these $200 \mathrm{c}$ between the two of you, regardless of the number marked on the ball.

Participant A receives the same instructions and, in addition, he/she knows which ball has been drawn before making a decision. In contrast, you will not know which ball has been drawn before making your decision.

Participant A's decision is not influenced by your choices. You will not be informed of Participant A's decision when making your own decision. 


\title{
Part 1: Comprehension Questionnaire
}

\author{
Click to remind me of the instructions
}

To make sure that the instructions are clear, please answer the following questions. If you have a doubt about the instructions, click on the button at the top of your screen.

Suppose that Participant A chooses the green button, and you choose to send $60 \AA$ to Participant A.

1) How much do you earn from this decision?

c

2) How much does Participant A earn from this decision?

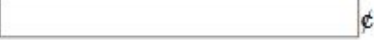

Suppose that Participant A chooses the orange button.

3) How much do you earn from this decision?

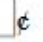

c

4) If the ball drawn by the computer program is marked with the number 15 , how much does Participant $\mathrm{A}$ earn from this decision?

5) If the ball drawn by the computer program is marked with the number 75 , how much does Participant $A$ earn from this decision? 


\title{
Part 1: Guess Participant A's expectations
}

\author{
Click to remind me of the instructions
}

You now have the opportunity to earn an additional $50 \%$ if you make the correct guess.

We ask Participant A to guess how much he/she expects to receive from you, if he/she chooses the green button. We would like to know how much you think Participant A expects to receive from you.

Your answer will be compared with the actual expectation of participant A. If you have guessed the amount correctly (plus or minus $15 \phi$ ), you will earn $50 \phi$ in addition to your other earnings.

Please pay attention to the different scenarios to answer the following questions.

Your guesses if Participant A chooses the green button:

If the number on the ball is 15 , Participant $\mathbf{A}$ has to give up $15 \dot{c}$ to let you decide the final earnings (green button). How much do you think Participant A expects to receive from you (by increments of $15 c$ ) in this case?

-- select an option -- $\checkmark t$

If the number on the ball is 75 , Participant $\mathbf{A}$ has to give up $75 \boldsymbol{c}$ to let you decide the final earnings (green button). How much do you think Participant A expects to receive from you (by increments of $15 \notin$ ) in this case?

-- select an option -- $\checkmark \phi$

At the end of the experiment, the answer corresponding to the true number marked on the ball will be selected for payment. 


\title{
Part 1: Your decisions
}

\author{
Click to remind me of the instructions
}

If Participant A chooses the green button, he/she entrusts you with $200 \phi$. In this case, you have to decide how much $\phi$ to send to Participant A out of these $200 \phi$ in two cases:

- If you learn that the number on the ball is $\mathbf{1 5}$ (Decision 15).

- If you learn that the number on the ball is 75 (Decision 75).

If you remain uninformed about the number marked on the ball, Participant A will receive the average of the amount indicated in Decision 15 and the amount indicated in Decision 75.

\section{Decision 15:}

If the number on the ball is 15 , you reported that Participant $A$ expects to receive $45 k$. How much would you send to Participant $\mathrm{A}$ in this case?

-- select an option -- $\checkmark d$

\section{Decision 75:}

If the number on the ball is 75 , you reported that Participant A expects to receive $90 \mathrm{c}$. How much would you send to Participant A in this case?

-- select an option -- $\checkmark$ c 


\section{Part 1: Instructions}

You have now the possibility to be informed about the number marked on the ball.

- If you learn that the number on the ball is 15 , Decision 15 is implemented: you keep $140 \mathrm{~d}$.

- If you learn that the number on the ball is 75 , Decision 75 is implemented: you keep $95 \mathrm{c}$.

You can also remain uninformed about the number marked on the ball:

- Then, the average of Decision 15 and Decision 75 is implemented: you keep 117.5\%.

The information is hidden in one of 4 envelopes. There are 2 silver envelopes and 2 gold envelopes.

One of these envelopes contains the number marked on the ball (either 15 or 75 ) and the other three envelopes are empty.

If the ball is marked with the number 15 , the information is in one of the two silver envelopes.

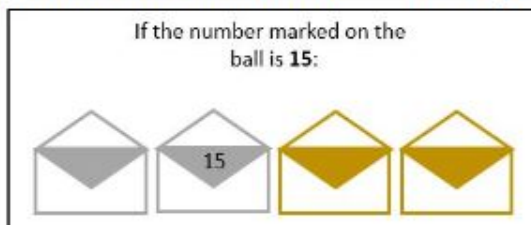

The information is in 1 of the silver envelopes. The other 3 envelopes are empty.
If the ball is marked with the number 75 , the information is in one of the two gold envelopes.

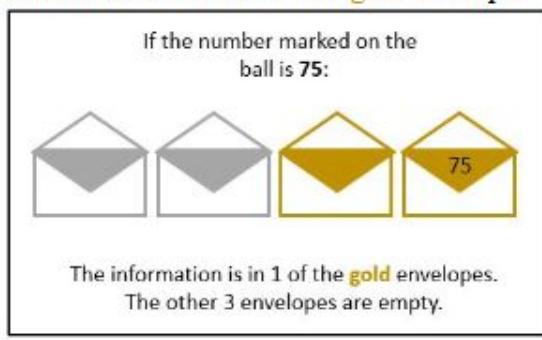

You will have to choose between three possibilities. You can choose to open:

- 1 silver envelope

- 1 gold envelope

- 1 silver envelope and 1 gold envelope

Your choice does not affect Participant A's decision. 


\section{Part 1: Instructions}

\section{Click to remind me of the instructions}

If you choose to open only 1 silver envelope, you will either:

- learn that the number on the ball is a 15: you keep 140e (Decision 15)

- remain uninformed about the number on the ball: you keep 117.5£ (average of Decisions 15 and 75)

If you choose to open only 1 gold envelope, you will either:

- learn that the number on the ball is a 75: you keep 95\& (Decision 75)

- remain uninformed about the number on the ball: you keep 117.5\& (average of Decisions 15 and 75)

If you choose to open 1 silver envelope and 1 gold envelope, you will either:

- learn that the number on the ball is a 15: you keep 140غ (Decision 15)

- learn that the number on the ball is a 75: you keep 95d (Decision 75)

- remain uninformed about the number on the ball: you keep $117.5 \notin$ (average of Decisions 15 and 75 ) 


\section{Part 1: Comprehension Questionnaire}

\section{Click to remind me of the instructions}

To make sure that the instructions are clear, please answer the following questions. If you have a doubt about the instructions, click on the button at the top of your screen.

1) What happens if you learn that the number on the ball is a 15 ?

Decision 15 is implemented.

() Decision 75 is implemented.

The average of Decision 15 and Decision 75 is implemented.

2) What happens if you remain uninformed about the number marked on the ball?

Decision 15 is implemented.

Decision 75 is implemented.

The average of Decision 15 and Decision 75 is implemented.

3) What happens if you open a silver envelope?

You either learn that the number on the ball is 15 or remain uninformed.

You either learn that the number on the ball is 75 or remain uninformed.

4) What happens if you open both a silver and a gold envelopes?

You learn for sure whether the number on the ball is 15 or 75 .

You either learn that the number on the ball is 15,75 or remain uninformed. 


\section{Part 1: Your decision}

\section{Click to remind me of the instructions}

Below are 2 silver envelopes and 2 gold envelopes.

You can now choose to open:

- 1 silver envelope

- 1 gold envelope

- 1 silver envelope and 1 gold envelope

Please pay attention to your choice since you will be asked to explain it at the end of the study.

Click on the envelope(s) that you wish to open. Click again on an envelope if you want to unselect it. You can try out several choices before your final choice.
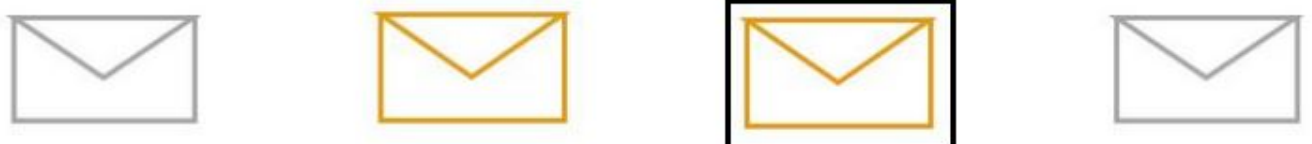

You chose to open 1 gold envelope. You will either:

- learn that the number on the ball is a 75 and keep 95d (Decision 75).

- remain uninformed and keep 117.5c (average of Decisions 15 and 75). 


\section{Part 1: Feedback}
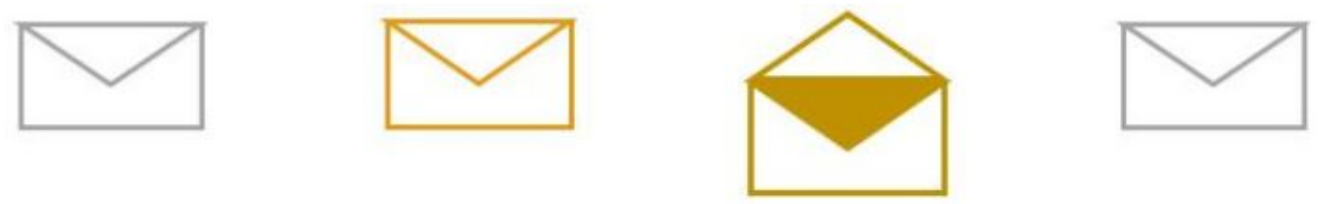

The envelope(s) you opened were empty. You remain uninformed of the ball drawn by the computer program.

Therefore, if Participant A chooses the green button, Participant A will receive the average between the amount you chose to send him or her in Decision 15 and the amount you chose to send him or her in Decision 75 , that is $(60+105) / 2=82.5$ c and you will keep 117.5 .

If Participant A chooses the orange button, you will receive $90 \mathrm{c}$. Participant $A$ will receive $15 \mathrm{c}$ if the number on the ball is 15 and 75 if the number on the ball is 75 .

\section{OK}

\section{Part 2}

All payments in this part are bonus payments, they do not include your fixed payment.

In this part of the study, you and all the other participants to the study must guess a number between 0 and 100 (inclusive). The participant whose chosen number is the closest to the two-third of the mean of all chosen numbers earns $100 \mathrm{~d}$. In case of a tie, the participant who earns the $100 \mathrm{~d}$ will be chosen at random by the computer program.

What is your chosen number? 


\section{Questionnaire}

In Part 1 of the study, how likely is it that Participant A chooses the green button (letting you decide the final earnings) if the number on ball was 15 ?

-- select an option -- $\vee$

In Part 1 of the study, how likely is it that Participant A chooses the green button (letting you decide the final earnings) if the number on ball was 75 ?

$$
\text { -- select an option -- } \checkmark
$$

In Part 1 of the study you were given the opportunity to receive information about the ball drawn by the computer program. The information was contained in one of four envelopes ( 2 silver and 2 gold). You chose to open 1 envelope(s). Please briefly explain why. You will earn $50 c$ to answer this question. (Optional)

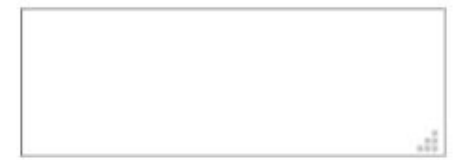

How would you rate the clarity of the questions in the study?

-- select an option -- $\vee$

Do you have any comments on the study? (Optional) 


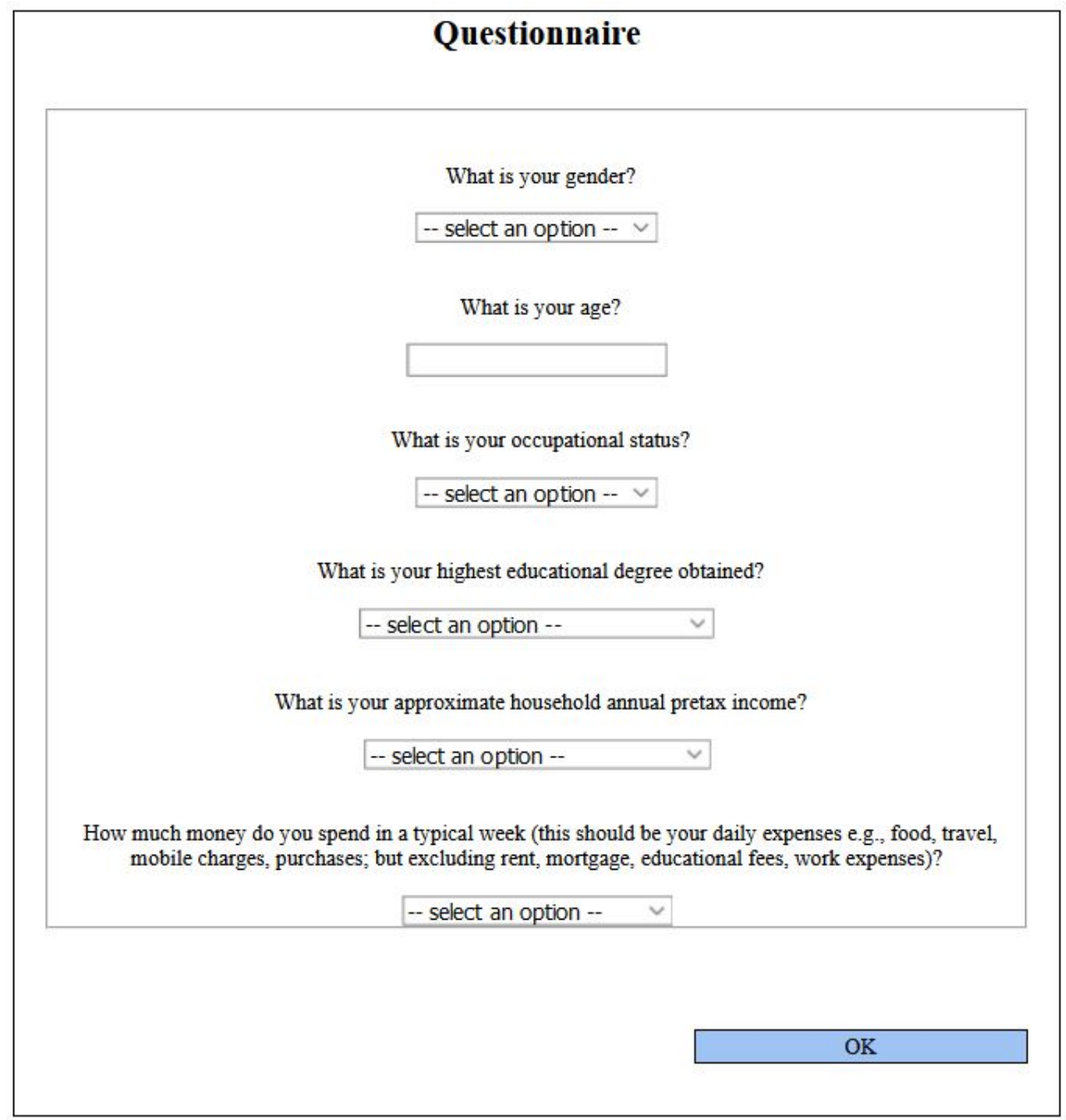

\section{Thank you for participating in this study!}

You have now completed the study.

Thank you!

You will receive your fixed payment within 48 hours and your bonus payment (i.e, the sum of earnings from the two parts) within a week from today.

If you have any questions concerning this study, you can contact us at rimbaud@gate.cnrs.fr

Your confirmation code to be entered on Mturk webpage is your Mturk worker ID. Please submit the HIT on Mturk with this ID

You can close this window now. 